\title{
THE ROLE OF SILVER NANOPARTICLES ON ACCELERATING HEALING OF SKIN WOUNDS IN RATS: HISTOLOGICAL AND IMMUNOHISTOCHEMICAL STUDY
}

\author{
Yasmin Ramadan, Maha Khaled El-Ashry, Ibtisam Ahmed Bahei-Eldin, \\ Azza Salah El Din Soliman, Nagwa Ebrahim El-Nefiawy and \\ Maha Moustafa Ahmed Zakaria
}

Human Anatomy and Embryology Department, Faculty of Medicine, Ain Shams University, Cairo, Egypt

Corresponding author Yasmin Ramadan

Mobile: (+2) 01111085675

E.mail:

ramadanyasmin@yahoo.com

Received: 30/6/2021

Accepted: 22/7/2021

Online ISSN: 2735-3540

\begin{abstract}
:
Background: Bad wound healing increases the burden to the patient and health care services. So any technology that improves the healing process has the potential to save billions in annual health care costs and preserves the patient quality of life. Silver nanoparticles (AgNps) have become of interest in biomedical applications, because of their antibacterial, antifungal, antiviral and anti-inflammatory activity.
\end{abstract}

Aim: was to investigate the role of AgNps on the healing process of skin wounds in adult male albino rats.

Material \& Methods: 72 male albino rats were subjected to excisional skin wounds $1.5 \mathrm{~cm}$ in diameter on their mid-backs. Then rats were divided into 4 groups 18 rats each; Group I(control): skin wounds were left to heal naturally. Group II: treated with methylcellulose hydrogel, Group III: treated with silver sulphadiazine

(dermazine cream) and Group IV: treated with AgNps in methylcellulose hydrogel. For each group 6 rats were sacrificed on $3 r d$, 7 th and 14th day post-wounding. Skin specimens from all groups were processed for paraffin blocks. Sections were stained with $H x \& E$ \& Mallory's trichrome and immune-stained with vascular endothelial growth factor (VEGF). Using image analysis software, the number of macrophages, newly formed blood vessels \& fibroblasts as well as area \% of collagen fibers deposition were assessed and statistically analyzed.

Results: In AgNps treated group re-epithelialization started on day 3 post-wounding and complete epithelialization and regeneration of the dermis was observed on day 14. The granulation tissue filling the wound area contained macrophages, newly formed blood vessels, fibroblasts and collagen fibers. The number of macrophages was statistically highest with significant difference in AgNps treated group (group IV) on day 3 post-wounding then was the lowest on days 7 and 14 compared with other groups. Neovascularization started on day 3 in all groups but was prominent on group as proved by results of VEGF immune staining. The newly formed blood vessels declined on day 14 in AgNps treated group and remained high in silver sulphadiazine group and showed maximum density in control group. The number of fibroblasts in group IV was maximum on day 7 postwounding \& decreased to minimum on day 14. The percent of collagen fibers deposition was statistically maximum in AgNps treated group with significant difference across all periods of the study 
compared to other groups. Conclusion: AgNps accelerated skin wound healing in rats.

Key words: rat, skin wound, silver sulphadiazine, silver nanoparticles.

\section{INTRODUCTION:}

The skin is the largest organ in the human body. It serves important functions including; protection of internal organs, sensory perception, immunologic surveillance, thermoregulation and control of fluid loss. ${ }^{1}$

A skin wound is defined as a disruption of normal tissue structure and function. There are a variety of causes which give rise to different types of wounds. These include; surgery (planned intervention), trauma (i.e., burns or lacerations), pathological changes in the body (i.e., circulatory vessels associated with leg ulcers), as well as wounds related to pressure (i.e., pressure ulcers) $)^{2}$.

Wound healing is a natural restorative response to tissue injury. It is a complex biologic process which involves mainly four different interlacing phases; homeostasis, inflammation, proliferation and maturation. ${ }^{3}$ In developing countries, wounds constitute a major problem as the rate of severe complications is high and financial resources are limited. This increases the popularity of natural therapy which represents the hope of finding a product with both higher efficacy and less cost for wound healing. ${ }^{4}$

Nanotechnology is becoming of increasing interest in medicine. Nanoparticles ( 1 to $100 \mathrm{~nm}$ in size) have a large surface area-to-volume ratio which increases their interaction with the tissues and offer improved penetration into wounds ${ }^{5}$. Different synthetic routes for silver nanoparticles (AgNps) lead to variable sizes, shapes, morphology, and even stability. Generally, these methods can be classified into three broad categories: physical, chemical and biological (or green) synthesis ${ }^{6}$. Recent studies have demonstrated the antibacterial, antiviral, antifungal, anti-inflammatory and anticancer effects of AgNps. ${ }^{7}$ Few studies were available regarding the role of $\mathrm{AgNps}$ in skin wound healing. 8,9

\section{AIM OF THE WORK:}

The present study was carried out to determine the role of silver nanoparticles in the healing process of excisional skin wounds in adult male albino rats using light microscopic, immuno-histochemical and morphometric methods.

\section{MATERIAL AND METHODS:}

\section{Experimental animals:}

In the present study 72 adult male albino rats weighing 200-250 g were obtained from the research center, Faculty of Medicine, Ain Shams University. Animals were maintained according to the principles and guidelines of the Committee of Animal Research Ethics (CARE). Rats were left for 2 week before any intervention to acclimatize to experimental conditions. The rats were exposed to 12 hours light/dark cycle and allowed free diet and water access (ad libitum) with suitable environmental conditions and good ventilation.

\section{Materials used in the present study included the following:}

\section{Silver nanoparticles (AgNps):}

AgNps were prepared at NanoTech Egypt Company in Dreamland, 6th October by chemical reduction method. A solution of silver nitrate was used as $\mathrm{Ag}^{1+}$ ions 
precursor. Polyvinyl-pyrrolidone was used as stabilizing agent and borohydride as mild reducing agent. The color of the solution turned slowly to grayish yellow indicating the reduction of $\mathrm{Ag}^{1+}$ ions to $\mathrm{Ag}$ nanoparticles. Its average size was $15 \mathrm{~nm}$ as recognized by Transmission Electron Microscope. ${ }^{10}$

\section{Methylcellulose (MC):}

Methylcellulose was purchased as a white powder from Nano Tech Egypt in Dreamland, 6th October and was used as a vehicle for the formation of silver nanoparticles methylcellulose hydrogel. ${ }^{11}$

\section{Silver sulphadiazine (SSD):}

Silver sulphadiazine was manufactured by Sandoz Company Cairo, Egypt in the form of dermazine cream (concentration $1 \%)$.

\section{Preparation of silver nanoparticles methylcellulose hydrogel:}

The methylcellulose based hydrogel was prepared by dispersing of $4 \mathrm{~g}$ of methylcellulose in $60 \mathrm{ml}$ of boiling distilled water followed by intensive stirring for 30min. Subsequently, dispersion of methylcellulose in boiling water was refilled by $36 \mathrm{ml}$ of cold distilled water and cooled down to $50^{\circ} \mathrm{C}$. This step led to formation of hydrogel phase. ${ }^{11}$ After cooling down to $50^{\circ} \mathrm{C}$, the prepared silver nanoparticles were added at a concentration of $0.2 \mathrm{mg}$ per gram of the hydrogel and gently mixed in a homogenizer resulting in a smooth formulation. ${ }^{8}$

\section{Preparation of excisional skin wound:}

The animals were anesthetized with intramuscular injection of $7 \%$ ketamine solution and $0.3 \%$ xylene solution at a ratio of $2: 1\left(0.2 \mathrm{~mL} / 100 \mathrm{~g} \mathrm{~b}\right.$. w.). ${ }^{\mathbf{1 2}}$ All care was taken to avoid any discomfort to the animals. Once anesthetized, the animals were placed in the prone position, the wound site was sterilized with an alcohol-iodine solution, and they were held while the dorsum was shaved .13 $^{2}$

A uniform circular area $1.5 \mathrm{~cm}$ in diameter was excised from the skin using a circular stamp and sterile scissor. The wounds were located in the middle portion of the median sagittal plane of the back of each animal and left uncovered. After recovery, animals were returned to their housing and allowed chow and water; every rat in a separate cage. ${ }^{\mathbf{8}}$

\section{Experimental groups:}

72 rats were divided into the following four groups: I, II, III, and IV (18 rats each). Then each group was divided into 3 subgroups (6 rats each), accordingly skin wound specimens were examined on days 3 , 7 and 14 post -wounding.

Group I (control group): rats with skin wound were kept untreated.

Group II (MC hydrogel treated group): rats with skin wound were topically treated once daily with $\mathrm{MC}$ hydrogel at a dose of $1000 \mathrm{mg} / \mathrm{kg} / \mathrm{b} . \mathrm{w}{ }^{\mathbf{1 4}}$

Group III (SSD treated group): rats of this group were topically treated once daily with SSD (dermazine cream) at a dose of 30 $\mathrm{mg} / \mathrm{kg} / \mathrm{b} \cdot \mathrm{w}^{15}$

Group IV (AgNps treated group): rats with skin wound were topically treated once daily with AgNps hydrogel at a dose of 2000 $\mathrm{mg} / \mathrm{kg} / \mathrm{b} . \mathrm{w}^{14}$

\section{Collection of specimens \&processing for light microscopic study:}

The rats were sacrificed on days 3,7 and 14 post-wounding by cervical dislocation under ether anesthesia. The entire wound area including the adjacent 2 $\mathrm{mm}$ of normal skin margins were excised. Specimens were fixed in $10 \%$ neutral formalin for 48 hours and were prepared for paraffin blocks. Serial sections of $5 \mu \mathrm{m}$ thickness were cut perpendicular to the surface of the wound. 
Some sections were stained with hematoxylin and eosin (Hx\&E) while other sections were stained with Mallory's trichrome for demonstrating the collagen fibers. ${ }^{16}$ Some sections were immuno-stained for vascular endothelial growth factor (VEGF). ${ }^{17}$

\section{Morphometry \& computer image analysis:}

Morphometric study was performed using NIH "Image J" computer image analysis software version $1.40 \mathrm{~g}$. Data were collected by examining six microscopic fields per slide, six slides per rat and six rats per group at X10 low power field for blood vessels count and area percent for collagen fibers deposition and at X40 high power field for fibroblasts and macrophages count.

\section{Statistical analysis:}

Statistical analysis was done using the SPSS software (Statistical Package for Social Studies- version 13.0). One-way analysis of variance (ANOVA) was employed to compare means in different groups with each other. Bonferroni Post Hoc test was used to detect significance between every two individual groups. The significance of the data was determined by the probability ( $P$. value). $\mathrm{P}>0.05$ was considered nonsignificant. $\mathrm{P} \leq 0.05$ was considered significant and $\mathrm{P} \leq 0.001$ was considered highly significant. ${ }^{18}$ Data were represented in Tables and Histograms, prepared by using MS Excel 2013.

\section{RESULTS:}

\section{Histological Results:}

In the present study, the histological findings of skin wound of the rats of group I (control group) and of the rats of group II (MC treated group) showed similar results on day 3, 7 and 14 post-wounding.

Examination of hematoxylin and eosin stained skin sections of the wound on day 3 post-wounding showed that re- epithelialization started only in the AgNps treated group where the epidermis at the wound edge was thickened and creeping to cover small adjacent wound area (Fig. 1). While in the control and SSD treated groups, there was no evidence of newly formed epidermis beneath the scab (no reepithelialization).

Day 7 post-wounding showed partial reepithelialization in control and SSD treated groups with short epithelial tongue (Figs. 2, 3). However in AgNps treated group, the newly formed epidermis was well arranged into four layers; stratum basal, stratum spinosum, stratum granulosum and finally stratum corneum (Figs.4, 5).

Day 14 post-wounding showed that reepithelialization was completed only in AgNps treated group with the appearance of sebaceous glands in the regenerated dermis; however partial re-epithelialization was observed in the control and SSD groups (Figs.6,7, 8).

Examination of $\mathrm{Hx}$ and $\mathrm{E}$ stained skin sections of the wound showed that the newly formed granulation tissue filled the wound gap in all groups however, its components; inflammatory cell infiltrate as polymorphnuclear leukocytes (PMNLs) with segmented nuclei and macrophages, newly formed blood vessels, spindle shaped fibroblasts and collagen fibers varied considerably among the studied groups across the three time points.

Inflammatory cell infiltrate were most pronounced on day 3 post-wounding, declined gradually on days 7 and 14 in the control, SSD and AgNps treated groups (Figs. 9, 10, 11, 12, 13, 14). Interestingly, AgNps treated group revealed the least observed inflammatory cell infiltrate allthrough the 3 time points.

In $\mathrm{Hx}$ and $\mathrm{E}$ stained skin sections, newly formed blood vessels (formed by angiogenesis) were seen in the granulation tissue on day 3 post-wounding (Figs. 9, 10, 
11) and day 7 (Figs. 12,13, 14) being much pronounced in AgNps treated group. On day 14 post-wounding new blood vessels were rare in $\mathrm{AgNps}$ treated group and numerous in control group and SSD treated group (Figs.6,7,8).

Examination of VEGF immuno-stained sections showed positive immune reaction in the form of brown cytoplasmic coloration at the endothelial lining of the newly formed blood vessels.On day 3 post-wounding, the immune reaction was weak involving few newly formed blood vessels in the control and SSD treated groups while in AgNps treated group the reaction appeared strong involving numerous newly formed blood vessels. However, on day 7 post-wounding, the immune reaction was moderate in the control group, strong in SSD and AgNps treated groups (Figs 15, 16, 17). However on day 14 post-wounding, the immune reaction decreased and became weak in $\mathrm{AgNps}$ treated groups and moderate in control group and SSD.

In $\mathrm{Hx}$ and $\mathrm{E}$ stained skin sections, fibroblasts were seen among the cellular elements of the granulation tissue. On day 3 post-wounding, fibroblasts were few in the control group (Fig. 9). On the other hand, they were numerous in SSD and AgNps treated groups (Figs. 10, 11). On day 7 postwounding, fibroblasts were found in the granulation tissue of all groups, but more presented in $\mathrm{AgNps}$ treated group (Figs. 12, 13, 14). On day 14 post-wounding, many fibroblasts were still persistent in the control and SSD treated groups while in AgNps treated group, fibroblasts were very few.

In $\mathrm{Hx}$ and $\mathrm{E}$ stained skin sections, on day 3 post-wounding, collagen fibers were thin and scarce in the control and SSD treated groups however, in AgNps treated group, many collagen fibers were haphazardly arranged and thick in the deep part of granulation tissue (Figs.9,10,11). In Mallory's trichrome stained sections On day 7 post wounding, collagen fibers were few and irregularly arranged in the control and SSD treated groups however, many regular parallel arranged collagen fibers were observed in AgNps treated group (Figs. 18, 19, 20).On day 14, many irregularly arranged thin bundles of collagen fibers were observed in the control group, thicker in SSD group while in AgNps treated group, collagen fibers were thin regularly arranged in the upper newly formed papillary dermis, thick wavy deeply stained in the lower reticular dermis(Figs. 21, 22, 23, 24).

\section{Morphometric Results:}

In the present study, skin wounds of the rats of group II (MC treated group)showed statistical non-significant difference $(\mathrm{P}>0.05)$ in the mean number of macrophages, blood vessels, fibroblasts and in the area percent of collagen fibers deposition on day 3, 7 and 14 post-wounding compared to the control group. Mean \pm SD of the four studied groups were expressed in Tables (1-4) and in Histograms (1 -4). 


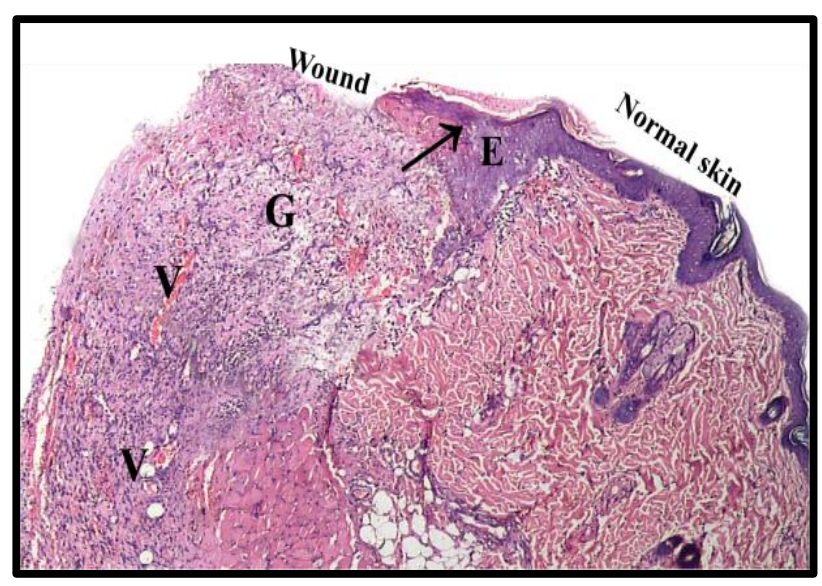

Fig. (1): A photomicrograph of a section of a rat's skin of group IV (AgNps treated group) on day 3 postwounding showing the wound area and the nearby normal skin. The epidermis (E) at the wound edge is thickened and creeping over the wound (initiation of re-epithelialization) (arrow). Newly formed granulation tissue $(\mathrm{G})$ is seen with numerous newly formed blood vessels $(\mathrm{V})$.

(Hx\&E, X40)

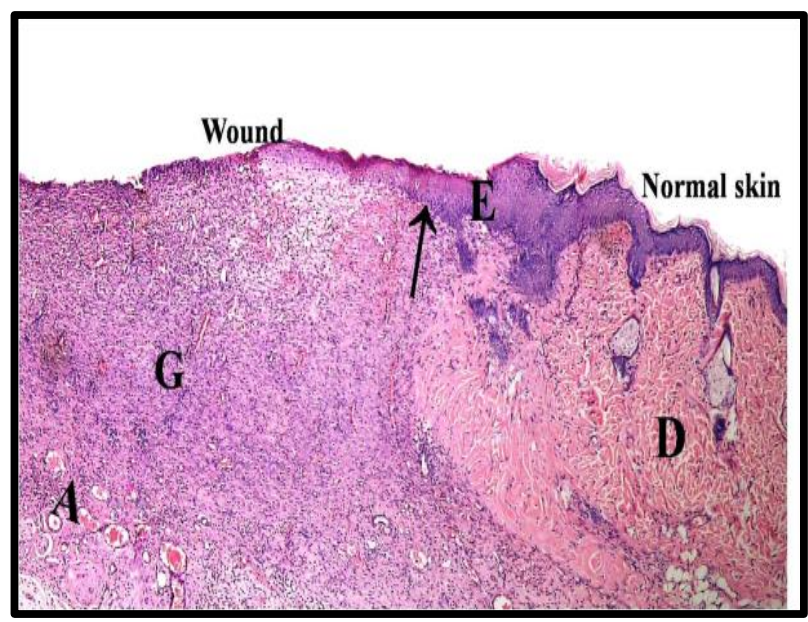

Fig. (3): A photomicrograph of a section of a rat's skin of group III (SSD treated group) on day 7 postwounding showing the wound and adjacent normal skin. The epidermis (E) at the wound edge is apparently thickened and is creeping to cover part of the wound area (start of re-epithelialization) (arrow). Granulation tissue (G) is seen with an area of angiogenesis (A). Dermis (D) of nearby normal skin is seen.

(Hx\&E, X40)

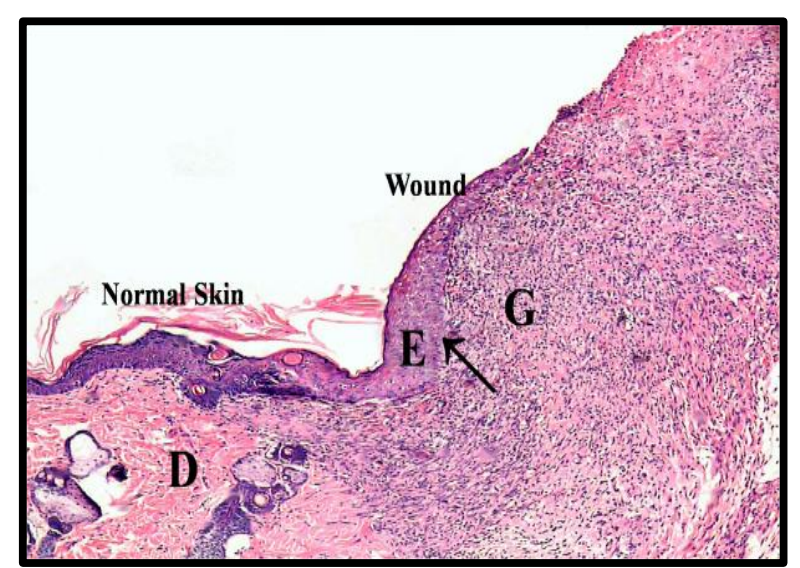

Fig. (2): A photomicrograph of a section of a rat's skin of group I (control) on day 7 post-wounding showing the wound and the nearby normal skin. Partial re-epithelialization (arrow) with newly formed epidermis (E) covering part of the wound area is seen with the underlying granulation tissue (G). Dermis (D) of nearby normal skin is also seen.

(Hx\&E, X40)

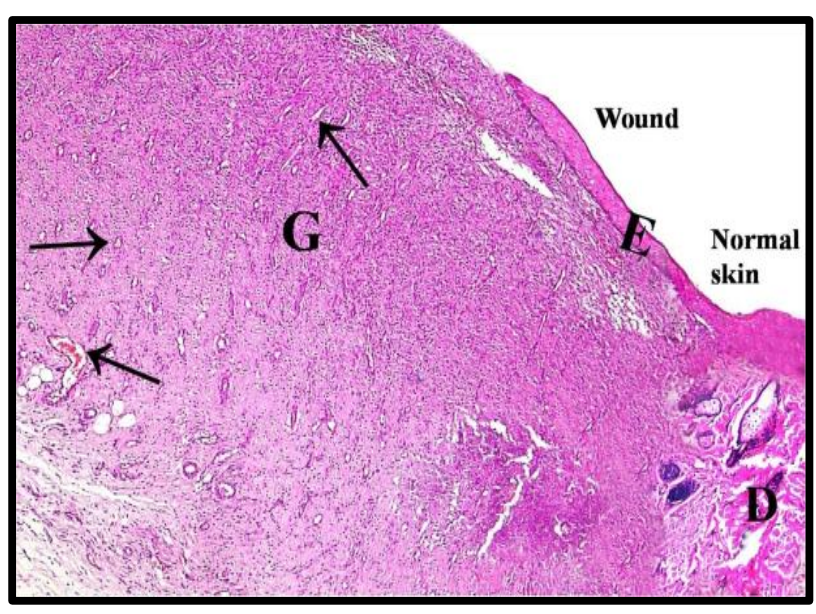

Fig. (4): A photomicrograph of a section of a rat's skin of group IV (AgNps) on day 7 post-wounding showing that the newly formed epidermis (E) extends to cover wide area of the wound (incomplete re-epithelialization). The granulation tissue $(G)$ is studded with numerous blood vessels (arrow). Dermis (D) of the adjacent normal skin is also seen.

(Hx\&E, X40) 


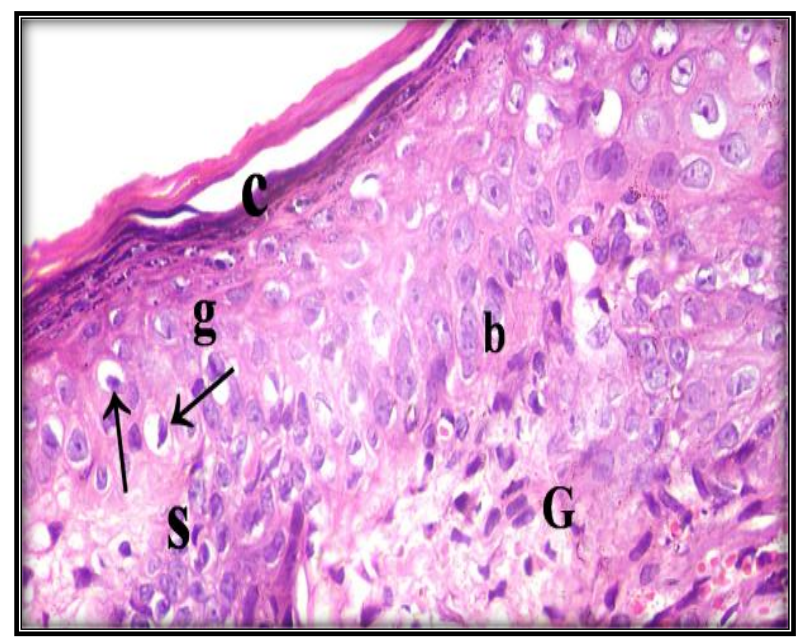

Fig. (5): A photomicrograph of a section of a rat's skin of group IV (AgNps) on day 7 post-wounding showing the newly formed epidermis with wellarranged layers; stratum basal (b), stratum spinosum (s), stratum granulosm (g) and stratum cornum (c). Notice some keratinocytes with pyknotic nuclei (arrow). The underlying granulation tissue $(\mathrm{G})$ is seen.

(Hx\&E, X400)

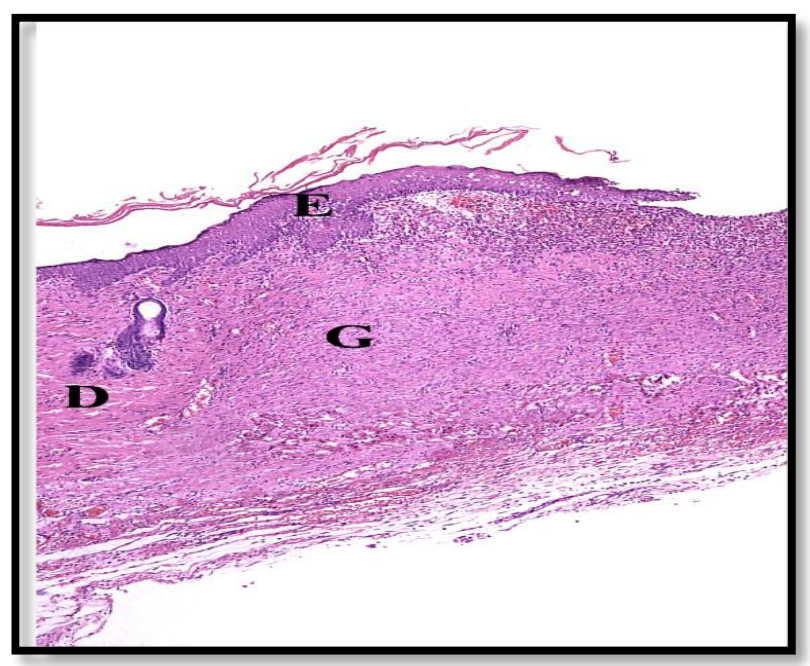

Fig. (7): A photomicrograph of a section of a rat's skin of group III(SSD treated group) on day 14 postwounding showing that the wound area is partially covered by epidermis (E) (incomplete re-epithelialization).Note the underlying granulation tissue with numerous blood vessels(G).(D) $=$ dermis of the nearby normal skin.

$(\mathbf{H x} \& \mathbf{E}, \mathbf{X 4 0})$

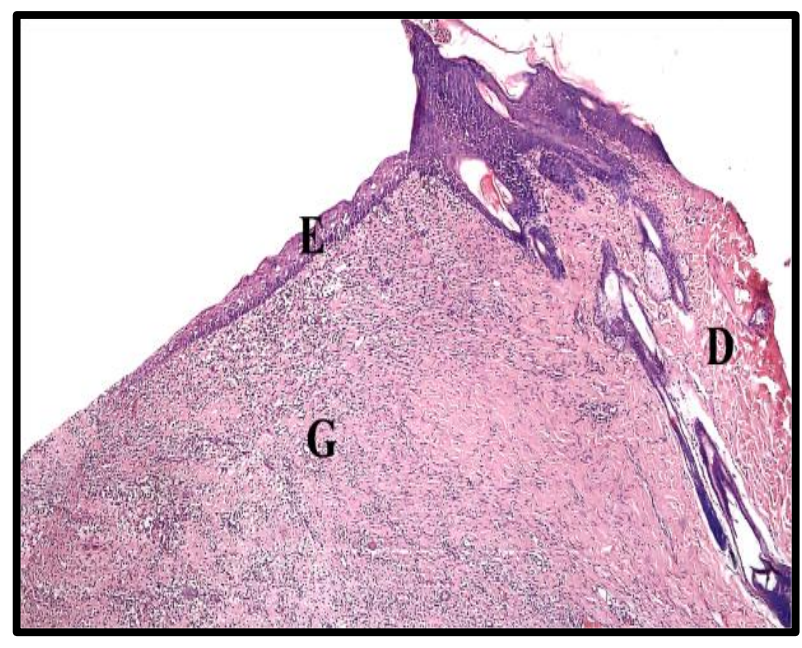

Fig. (6): A photomicrograph of a section of a rat's skin of group I(control) on day 14 post-wounding showing incomplete re-epithelialization of the wound area with the newly formed epidermis (E). Note the underlying granulation tissue with numerous blood vessels(G). (D) $=$ dermis of the nearby normal skin.

(Hx\&E, X40)

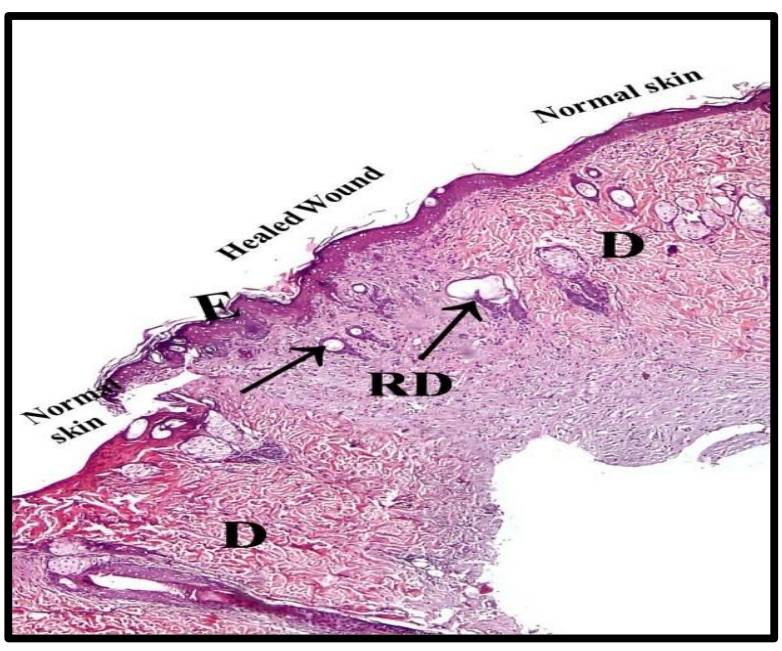

Fig. (8): A photomicrograph of a section of a rat's skin of group IV(AgNps) on day 14 post-wounding showing that the wound area is completely covered by newly formed epidermis (complete re-epithelialization).The underlying regenerated dermis (RD) containing sebaceous glands (arrow) is seen. Dermis (D) of nearby normal skin is also seen on both sides of the wound.

(Hx\&E, X40) 


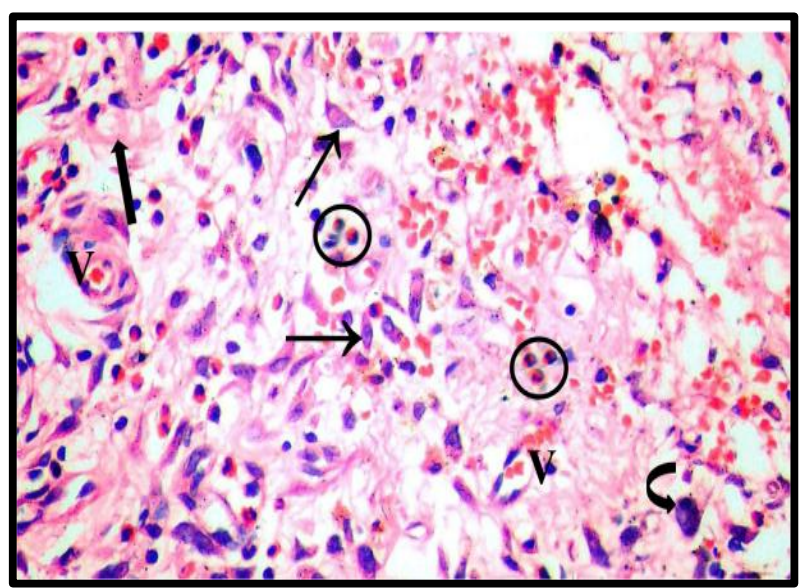

Fig. (9): A photomicrograph of a section of a rat's skin of group I (control) on day 3 post-wounding showing some of the content of the granulation tissue; inflammatory cell infiltrate; PMNLs (circle) and few macrophages (curved arrow) and newly formed blood vessels (V). Fibroblasts (thin arrow) and scattered collagen fibers (thick arrow) are seen.

(Hx \&E, X400)

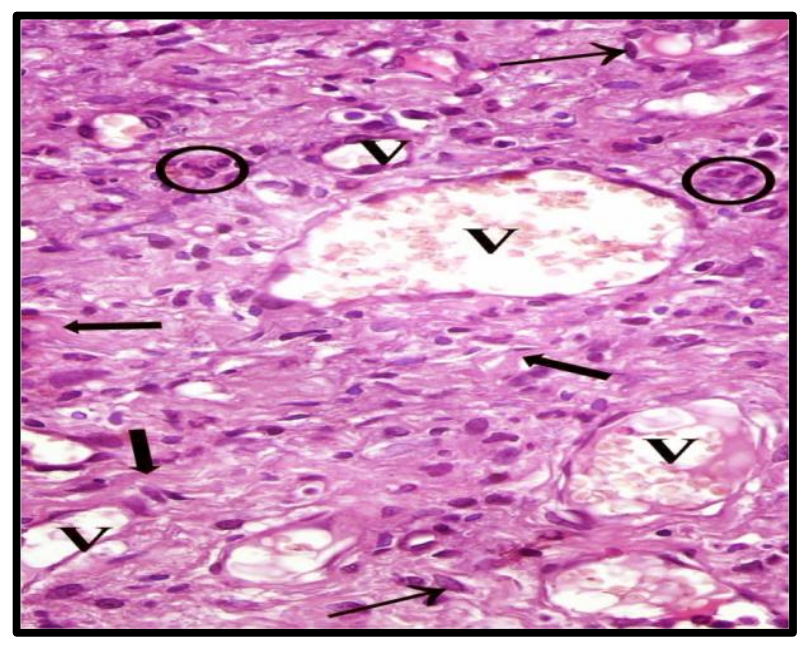

Fig. (11): A photomicrograph of a section of a rat's skin of group IV(AgNps treated group) on day 3 post-wounding showing that the granulation tissue is filled with numerous newly formed congested blood vessels (V), inflammatory cell infiltrate, PMNLs (circle) and fibroblasts (thin arrow) and abundant collagen fibers (thick arrow).

(Hx \&E, X 400)

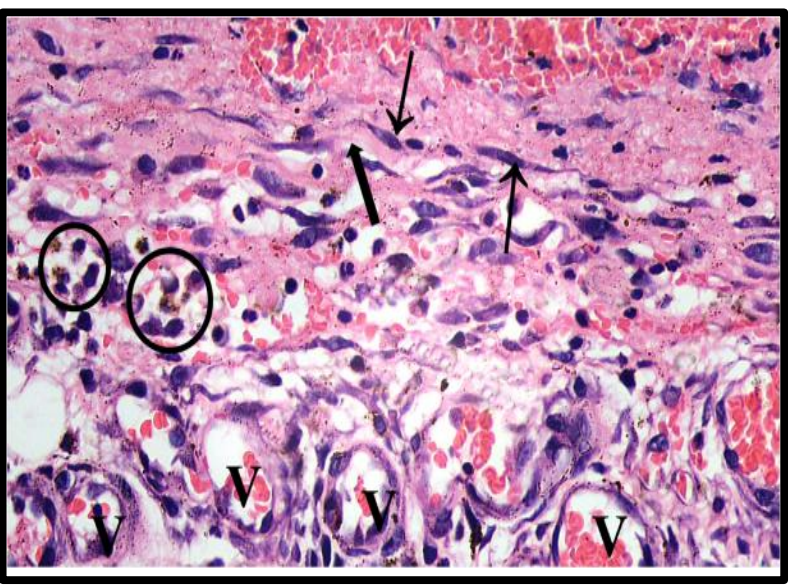

Fig. (10): A photomicrograph of a section of a rat's skin of group III(SSD treated group) on day 3 post. wounding showing that the granulation tissue contains numerous newly formed congested blood vessels (V), inflammatory cell infiltrate (circle) and many fibroblasts (thin arrow). Bundles of collagen fibers (thick arrow) are also seen. (Hx \&E, X400)

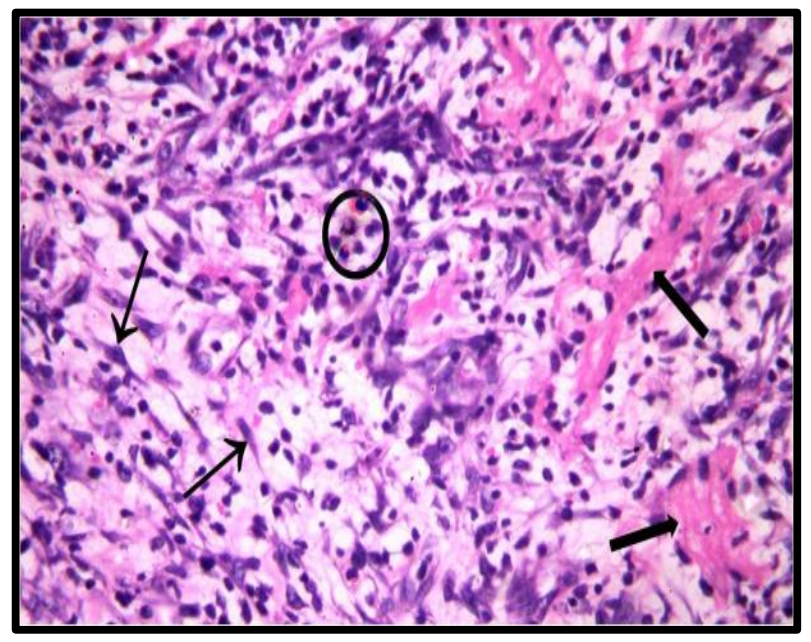

Fig. (12): A photomicrograph of a section of a rat's skin of group I(control) on day 7 post-wounding showing heavy inflammatory cell infiltrate (circle) and few bundles of collagen fibers (thick arrow) deposited in the granulation tissue. Fibroblasts (thin arrow) are also seen.

(Hx \&E, X400) 


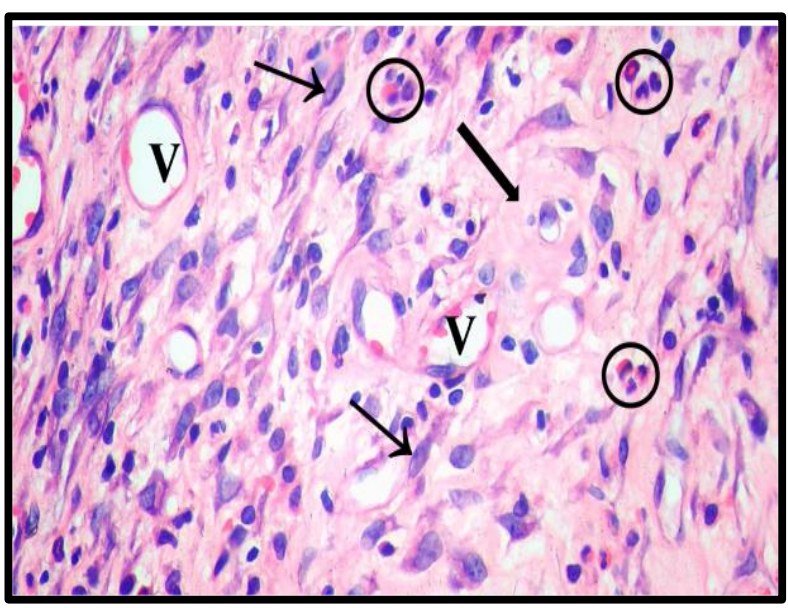

Fig. (13): A photomicrograph of a section of a rat's skin of group III(SSD treated group) on day 7 postwounding showing numerous newly formed blood vessels (V), and inflammatory cell infiltrate PMNLs (circle) in the granulation tissue. Fibroblasts (thin arrow) and network of thin collagen fibers (thick arrow) are also seen.

(Hx \&E, X400)

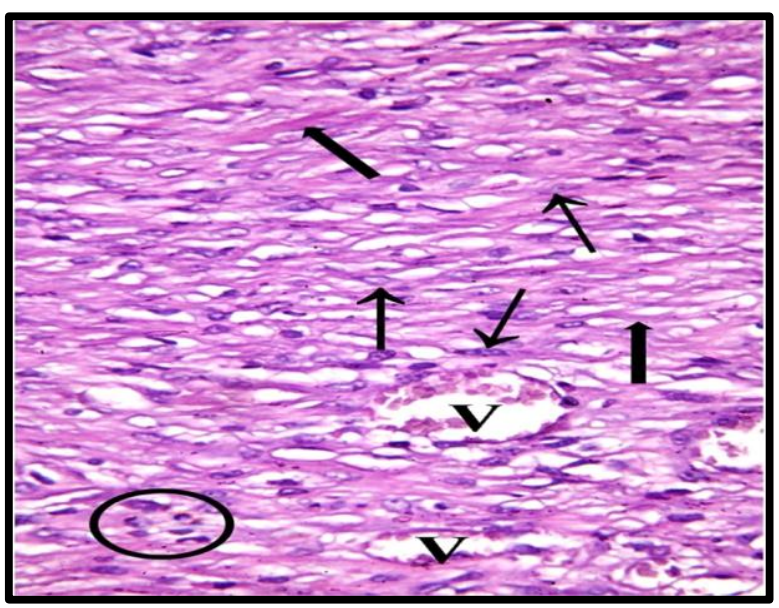

Fig. (14): A photomicrograph of a section of a rat's skin of group IV(AgNps) on day 7 post-wounding showing that the granulation tissue is filled with many newly formed blood vessels (V), few inflammatory cell infiltrate (circle), numerous fibroblasts (thin arrow) and bundles of collagen fibers regularly arranged parallel to the surface (thick arrow).

$(\mathrm{Hx \& E}, \mathrm{X400})$

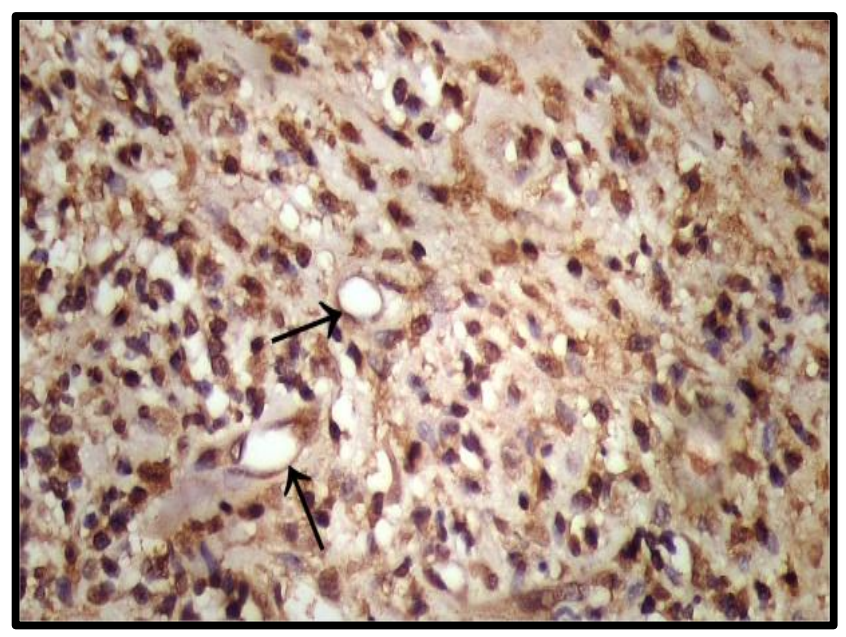

Fig. (15): A photomicrograph of a section of a rat's skin of group I(control) on day 7 post-wounding showing the granulation tissue with moderate positive immuno-stained endothelial cells at lining of few newly formed blood vessels (thin arrow).

(VEGF，X400)

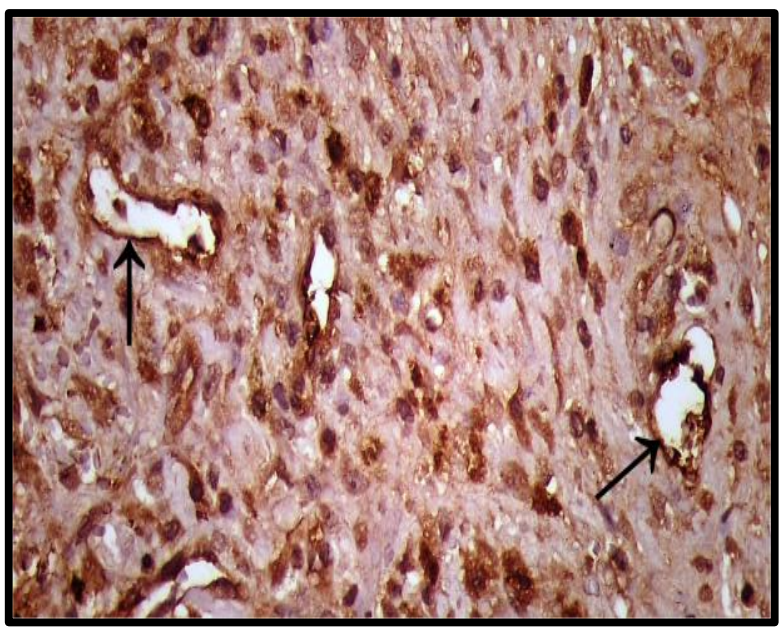

Fig. (16): A photomicrograph of a section of a rat's skin of group III(SSD treated group) on day 7 post-wounding showing strong positive immune reaction at lining of the newly formed blood vessels (thin arrow) in the granulation tissue.

(VEGF, X400) 


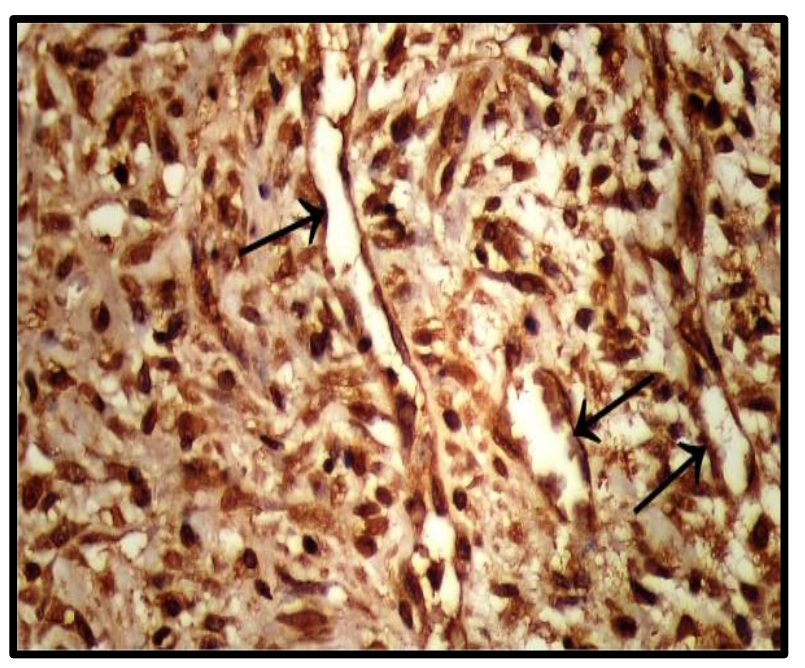

Fig. (17): A photomicrograph of a section of a rat's skin of group IV(AgNps) on day 7 post-wounding showing strong positive cytoplasmic immune reaction at endothelial lining of the newly formed blood vessels (thin arrow) in the granulation tissue.

(VEGF, X 400)

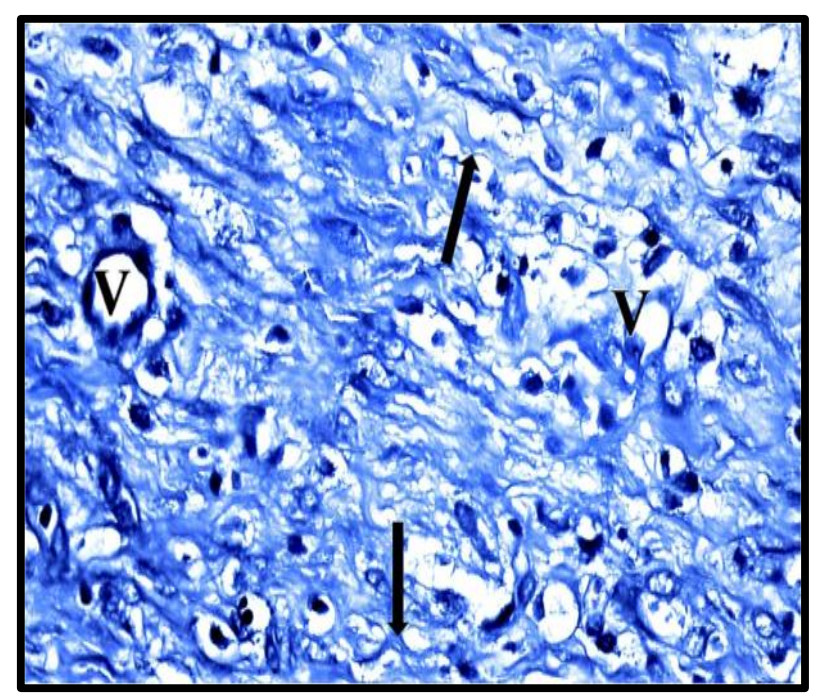

Fig. (19): A photomicrograph of a section of a rat's skin of group I II(SSD treated group) on day 7 post-wounding showing that the granulation tissue contains irregularly arranged bundles of collagen fibers (arrow) and blood vessels (V).

(Mallory's trichrome, $X$ 400)

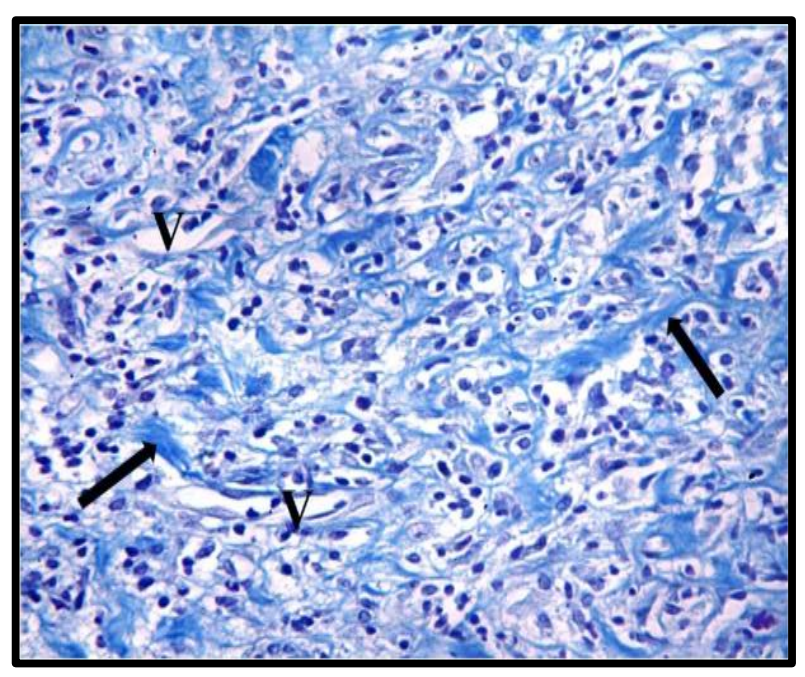

Fig. (18): A photomicrograph of a section of a rat's skin of group I(control) on day 7 post-wounding showing few irregularly arranged bundles of collagen fibers (arrow) and newly formed blood vessels (V) in the granulation tissue.

(Mallory's trichrome, $X$ 400)

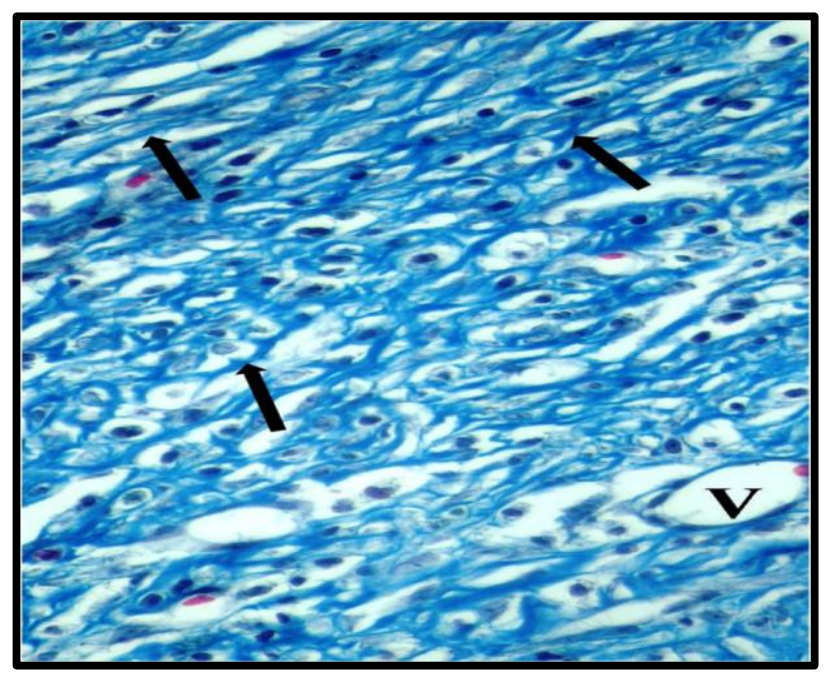

Fig. (20): A photomicrograph of a section of a rat's skin of group $\mathrm{IV}(\mathrm{AgNps}$ treated group) on day 7 post-wounding showing that the newly formed granulation tissue is filled with apparently numerous thin bundles of regularly arranged collagen fibers nearly parallel to the surface(arrow). Blood vessels (V) are also seen.

(Mallory's trichrome, $X$ 400) 


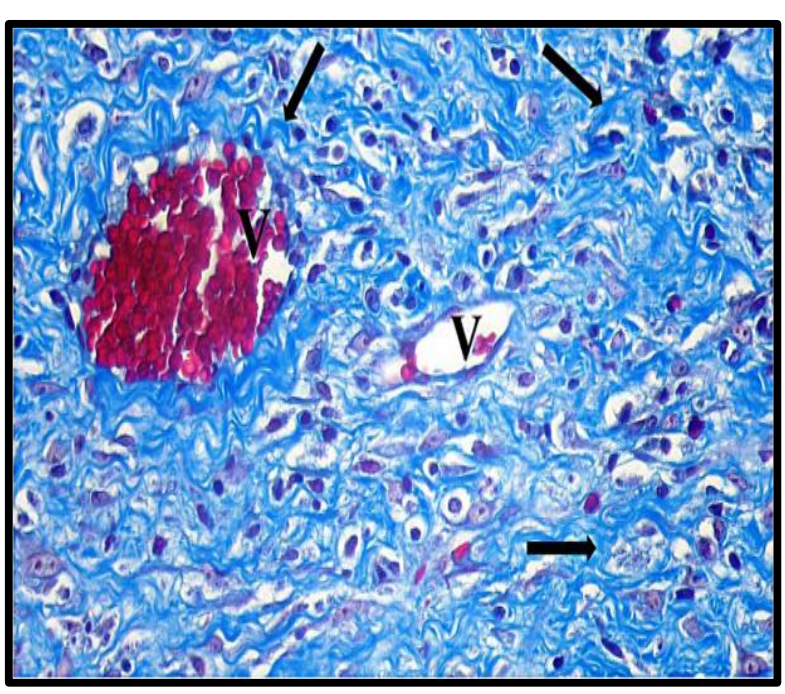

Fig. (21): A photomicrograph of a section of a rat's skin of group I(control) on day 14 post-wounding showing apparently irregularly arranged thin bundles of collagen fibers (thick arrow) dispersed around and between persistent blood vessels (V) in the deep part of the granulation tissue.

(Mallory's trichrome, X 400)

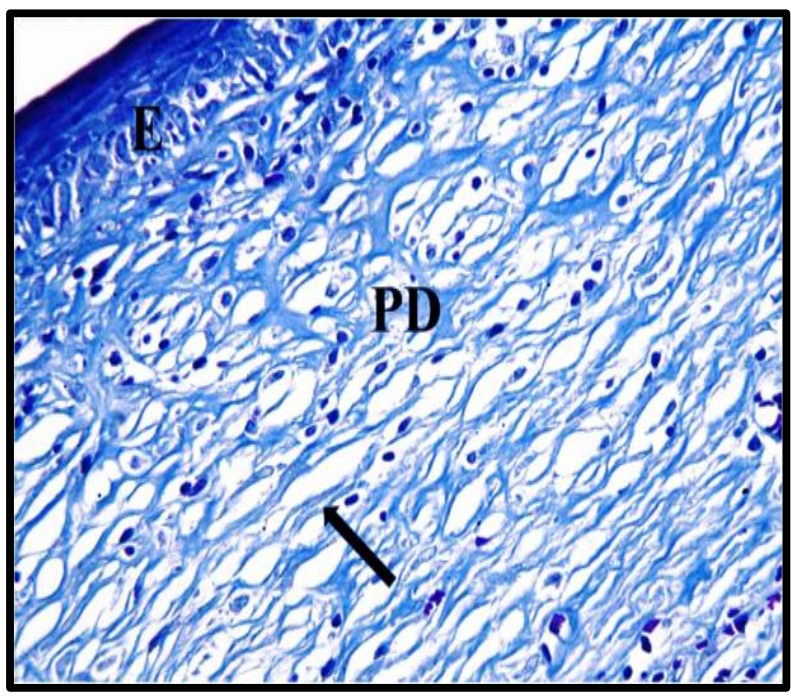

Fig. (23): A photomicrograph of a section of a rat's skin of group $\operatorname{IV}(\mathrm{AgNps}$ treated group) on day 14 post-wounding showing that the papillary dermis (PD) contains thin regularly arranged bundles of fine collagen fibers parallel to the surface (arrow). Part of the newly formed epidermis (E) is seen

(Mallory's trichrome, $X$ 400)

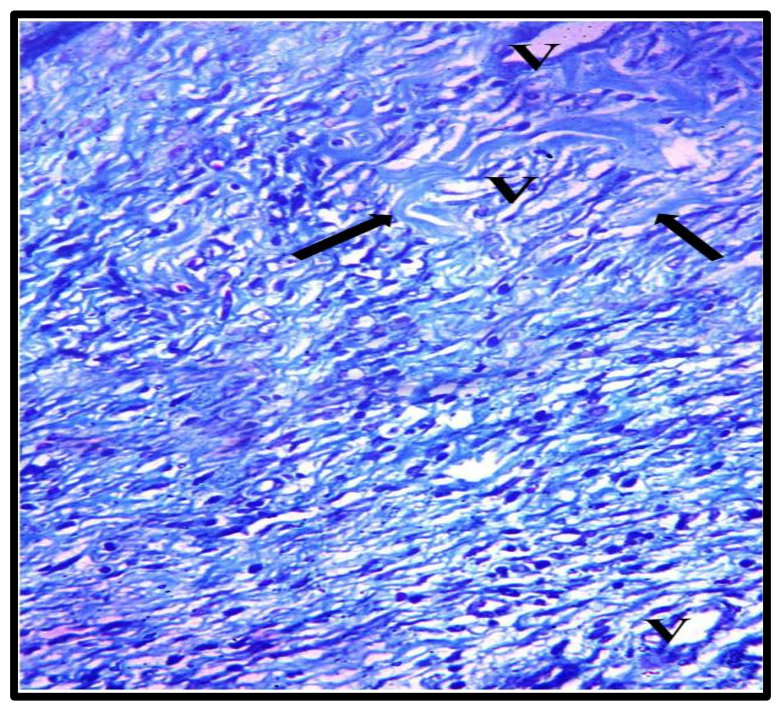

Fig. (22): A photomicrograph of a section of a rat's skin of group I II(SSD treated group) on day 14 post-wounding showing bundles of collagen fibers (thick arrow) apparently thick around persistent blood vessels (V). (Mallory's trichrome, X 400)

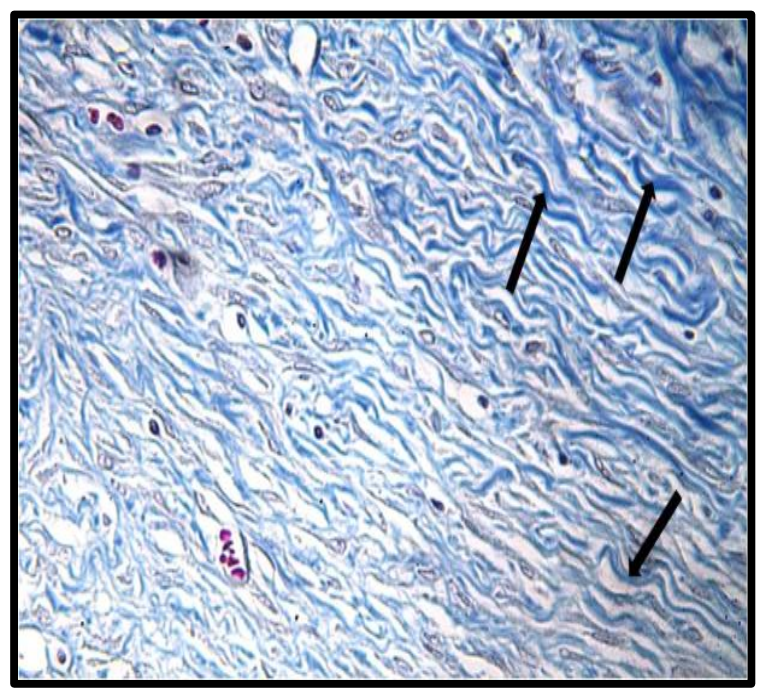

Fig. (24): A photomicrograph of a section of a rat's skin of group IV(AgNps treated group) on day 14 post-wounding showing that the newly formed reticular dermis is filled with thick wavy deeply stained regularly arranged bundles of collagen fibers (arrow). (Mallory's trichrome, X 400) 
Table (1): The mean number of macrophages among the four study groups

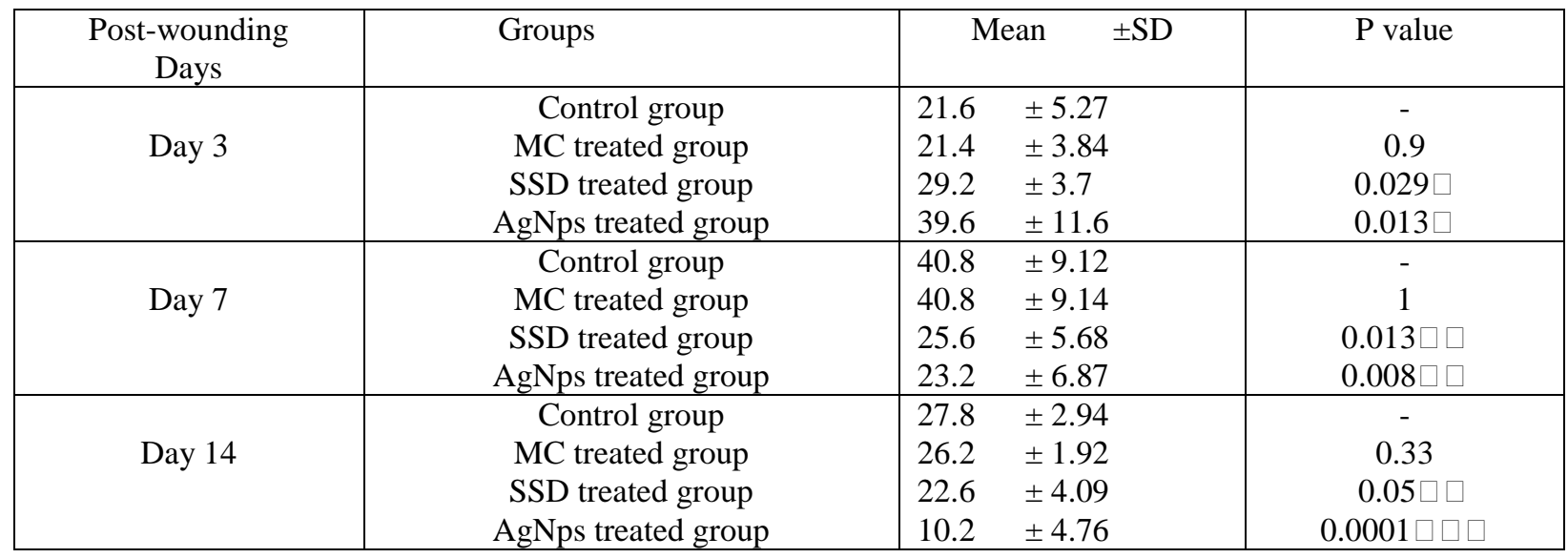

$\square=$ significant increase compared to control group $(\mathrm{P} \leq 0.05)$.

$\square \square=$ significant decrease compared to control group $(\mathrm{P} \leq 0.05)$.

$\square \square \square=$ highly significant decrease compared to control group $(\mathrm{P} \leq 0.001)$.

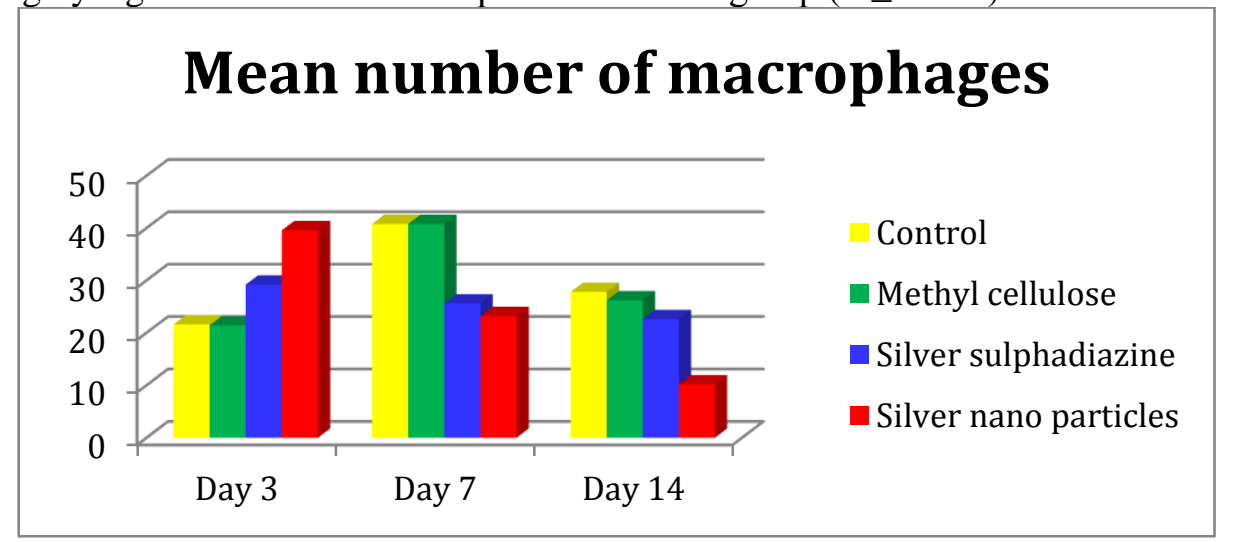

Histogram (1): The mean number of macrophages among the four study groups

Table (2): Mean number of newly formed blood vessels among the four study groups

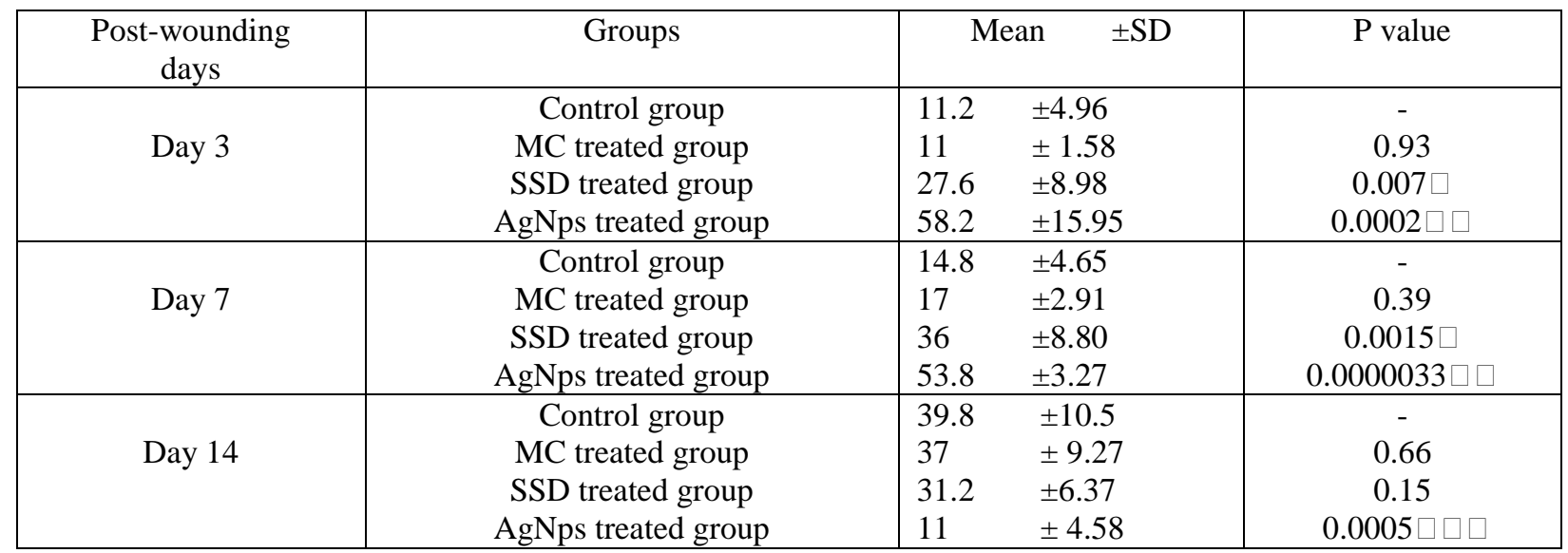

$\square=$ significant increase compared to control group $(\mathrm{P} \leq 0.05)$.

$\square \square=$ highly significant increase compared to control group $(\mathrm{P} \leq 0.001)$.

$\square \square \square=$ highly significant decrease compare to control group $(\mathrm{P} \leq 0.001)$. 


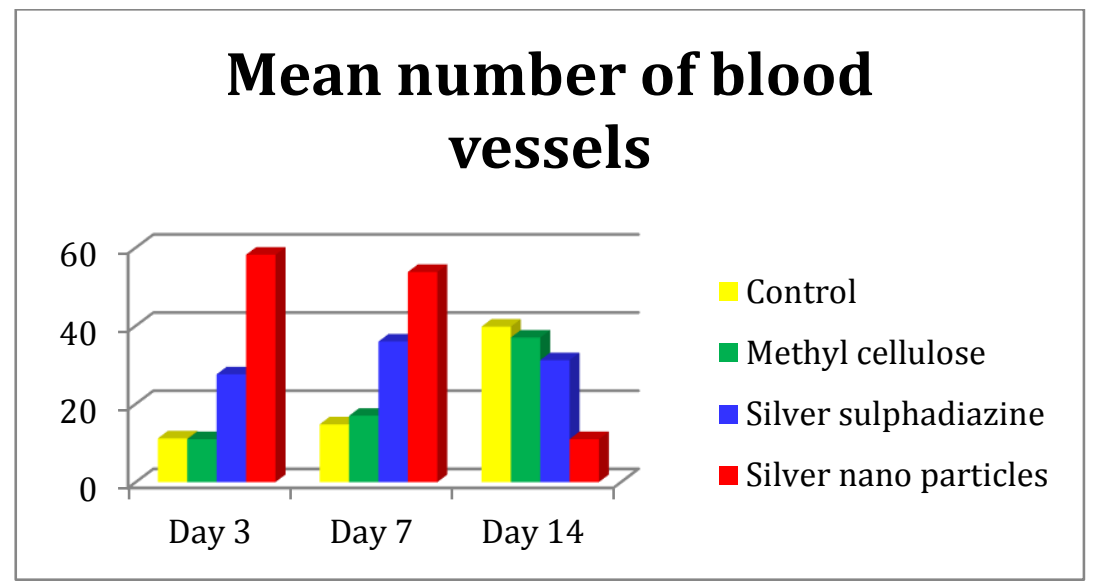

Histogram (2): The mean number of newly formed blood vessels among the four study groups.

Table (3): Mean number of fibroblasts among the four study groups

\begin{tabular}{|c|c|c|c|}
\hline $\begin{array}{l}\text { Post-wounding } \\
\text { Days }\end{array}$ & Groups & Mean $\quad \pm \mathrm{SD}$ & $P$ value \\
\hline Day 3 & $\begin{array}{c}\text { Control group } \\
\text { MC treated group } \\
\text { SSD treated group } \\
\text { AgNps treated group }\end{array}$ & $\begin{array}{ll}10 & \pm 1.87 \\
9.8 & \pm 1.92 \\
18.4 & \pm 3.97 \\
29.4 & \pm 7.71 \\
\end{array}$ & $\begin{array}{c}- \\
0.87 \\
0.002 \square \\
0.0005 \square \square\end{array}$ \\
\hline Day 7 & $\begin{array}{c}\text { Control group } \\
\text { MC treated group } \\
\text { SSD treated group } \\
\text { AgNps treated group }\end{array}$ & $\begin{array}{ll}24.2 & \pm 4.32 \\
26 & \pm 5 \\
28 & \pm 4.84 \\
55.4 & \pm 9.55 \\
\end{array}$ & $\begin{array}{c}- \\
0.55 \\
0.22 \\
0.0001 \square \square\end{array}$ \\
\hline Day 14 & $\begin{array}{c}\text { Control group } \\
\text { MC treated group } \\
\text { SSD treated group } \\
\text { AgNps treated group }\end{array}$ & $\begin{array}{ll}22.6 & \pm 3.36 \\
21 & \pm 3.16 \\
20.8 & \pm 4.08 \\
12.6 & \pm 1.94 \\
\end{array}$ & $\begin{array}{c}- \\
0.461 \\
0.468 \\
0.0004 \square \square \square\end{array}$ \\
\hline
\end{tabular}

$\square=$ significant increase compared to control group $(\mathrm{P} \leq 0.05)$.

$\square \square=$ highly significant increase compared to control group $(\mathrm{P} \leq 0.001)$.

$\square \square \square=$ highly significant decrease compared to control group $(\mathrm{P} \leq 0.001)$.

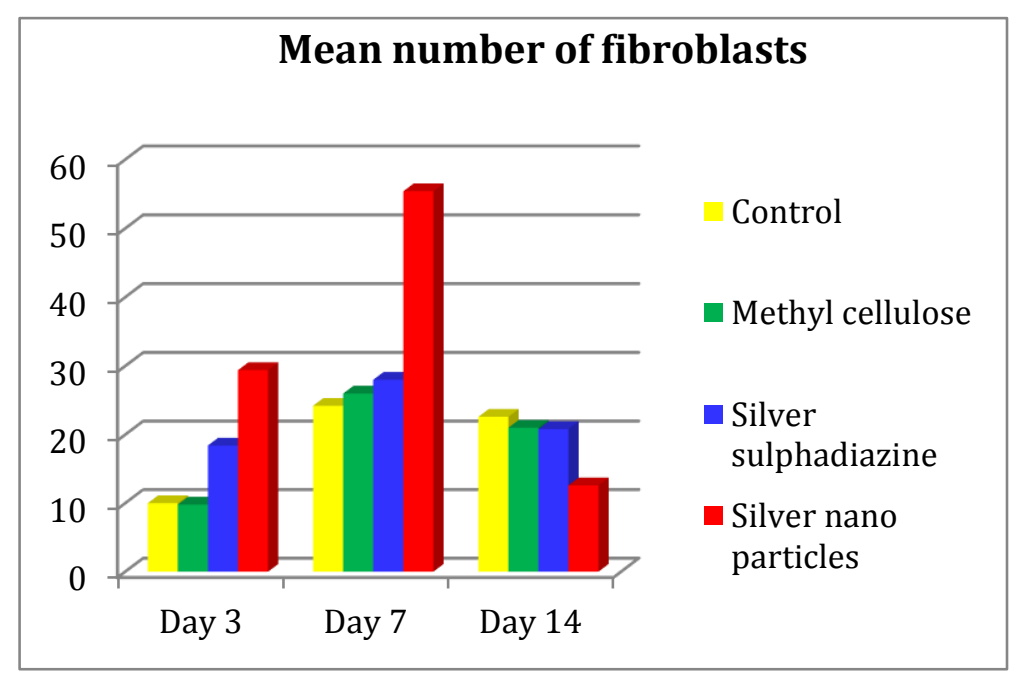

Histogram (3): The mean number of fibroblasts among the four study groups 
Table (4): The mean area percent of collagen fibers deposition among the four study groups

\begin{tabular}{|c|c|c|c|}
\hline Post-wounding days & Groups & Mean $\quad \pm$ SD & $\mathrm{P}$ value \\
\hline Day 3 & $\begin{array}{c}\text { Control group } \\
\text { MC treated group } \\
\text { SSD treated group } \\
\text { AgNps treated group }\end{array}$ & $\begin{array}{ll}13.05 & \pm 6.6 \\
12.96 & \pm 6.86 \\
24.8 & \pm 5.83 \\
28.58 & \pm 4.16 \\
\end{array}$ & $\begin{array}{c}- \\
0.98 \\
0.017 \square \\
0.002 \square\end{array}$ \\
\hline Day 7 & $\begin{array}{c}\text { Control group } \\
\text { MC treated group } \\
\text { SSD treated group } \\
\text { AgNps treated group }\end{array}$ & $\begin{array}{ll}26.7 & \pm 5.33 \\
24.9 & \pm 7.14 \\
32.34 & \pm 4.7 \\
39.6 & \pm 3.9 \\
\end{array}$ & $\begin{array}{c}- \\
0.65 \\
0.12 \\
0.002 \\
\end{array}$ \\
\hline Day 14 & $\begin{array}{c}\text { Control group } \\
\text { MC treated group } \\
\text { SSD treated group } \\
\text { AgNps treated group }\end{array}$ & $\begin{array}{ll}31.6 & \pm 5.81 \\
30.5 & \pm 6.9 \\
35.5 & \pm 7.69 \\
45.9 & \pm 5.66\end{array}$ & $\begin{array}{c}- \\
0.79 \\
0.38 \\
0.004\end{array}$ \\
\hline
\end{tabular}

$\square=$ significant increase +compared to control group $(\mathrm{P} \leq 0.05)$.

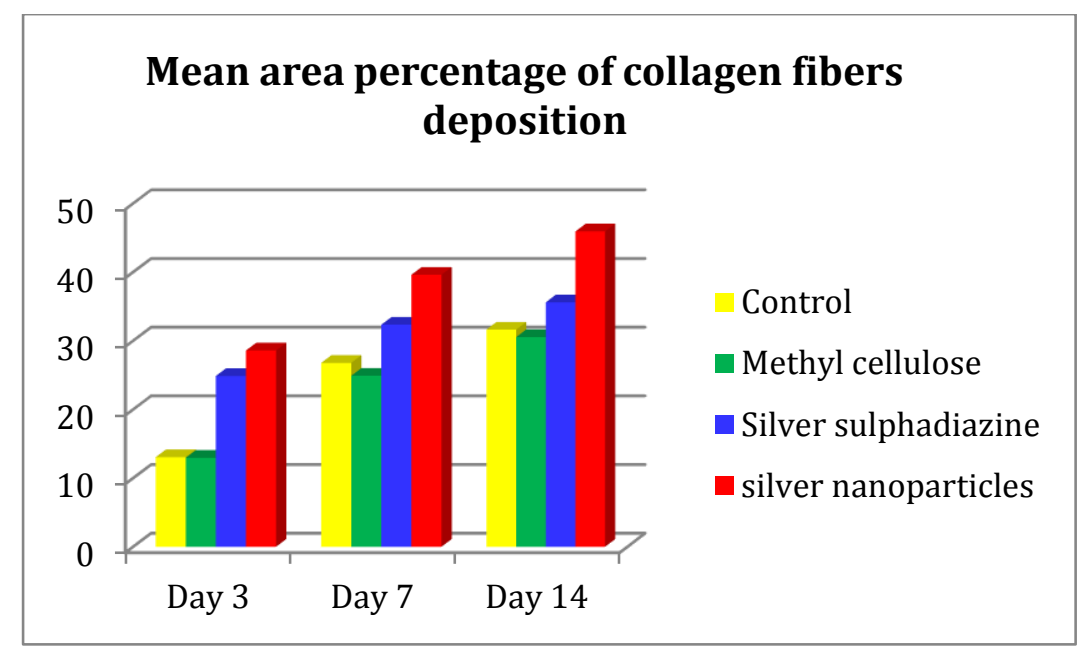

Histogram (4): The mean area percent of collagen fibers deposition among the four study groups

\section{DISCUSSION:}

The present study was designed to evaluate the effect of silver nanoparticles on the healing process of excisional skin wounds in adult albino rat. A rat model was used in this study as rats are docile and available. Also, their skin is elastic, redundant and lacks adherence to the underlying structures (loose-skinned animals) allowing better wound contraction and wound healing. Rats also possess subcutaneous panniculus carnosus muscle which contributes to wound healing by enhancing both wound contraction and collagen formation. ${ }^{19,20}$
In this work, excisional skin wound was preferred because this had provided a cleaner wound than a burn wound, thereby decreasing the potential for complications from infection ;therefore, aiding wound healing. ${ }^{21}$ Also the excisional model is more appropriate for better histological evaluation due to significantly broader morphological changes which occur during the healing process .22, 23

There are many routes for AgNps synthesis; physical, chemical and biological synthesis. In this study, AgNps were synthesized chemically as it was an available and easy route although it is expensive. Also, Hendi (2011) ${ }^{24}$ and Fawzy et al. 
(2018) ${ }^{\mathbf{2 5}}$ used the same way of synthesis. A major advantage of the chemical synthetic route is the high yield of AgNps in contrast to other routes.$^{26}$

In this study, wounds were examined in rats which were divided into four separate groups; control (nontreated group) and three different treated groups; methylcellulose (MC), silver sulphadiazine (SSD) and silver nanoparticles (AgNps) treated groups at three different time points (day 3, day 7 and day 14 post-wounding). Khafaga et al. (2018) ${ }^{27}$ studied also the effect of topical application of silver nanoparticles in equine wound healing on similar three time points.

In the present study initiation of reepithelialization was observed on day 3 postwounding in $\mathrm{AgNps}$ treated group and on day 7 in all other groups. Complete reepithelialization was found only in $\mathrm{AgNps}$ treated group on day 14 post-wounding in contrast to the other groups where complete re-epithelialization was not achieved. The epidermis in AgNps treated group on day 14 post-wounding regained its normal thickness with full differentiation of its keratinocytes into four layers with the appearance of skin appendages as sebaceous glands.

Naraginti et al. (2016) ${ }^{8}$ found also that complete epithelialization was achieved on day 14 post-wounding when they studied the effect of topical application of green synthesized silver nanoparticles in albino wistar rats. On the contrary complete epithelialization was achieved on day 9 postwounding by Sundaramoorthi et al. $(\mathbf{2 0 0 9})^{28}$ when they studied the effect of silver nanoparticles on wound healing in albino rats. This discrepancy may be attributed to the way of synthesis of the AgNps used, where they used the biological method of synthesis in addition to that, they had covered the wound with wound dressing and changed it daily. Also, they depended on falling of scab as the end point of complete epithelialization without any histological studies.
Early re-epithelialization is crucial for wound healing to restore the intact epidermal barrier, thus preventing infection and excessive moisture loss. Therefore, failure of re-epithelialization causes impaired wound healing ${ }^{29}$.

Pastar et al. (2014) ${ }^{30}$ explained that, wound re-epithelialization is a multifactorial process. It requires keratinocytes migration, proliferation and differentiation. Keratinocytes at the wound edge must first lose their adhesion to each other and to the basal lamina to support their migration over the granulation tissue to cover the denuded area. Then, keratinocytes start to proliferate to ensure an adequate supply of cells. Once the wound area is covered, contact inhibition causes keratinocytes to stop migration and triggers their differentiation into stratified squamous keratinizing epidermal cells.

Bhagavathy \& Kancharla (2016) ${ }^{31}$ found that AgNps can trigger reepithelialization through signaling pathway, which is one of the most commonly used pathways in animal cells.

In the present work, granulation tissue in the wound area on day 3 post-wounding showed cellular elements (PMNLs, macrophages and fibroblasts), newly formed blood vessels formed by angiogenesis and collagen fibers in all examined groups. Murthy et al. (2013) ${ }^{32}$ and Park and Barbul (2004) ${ }^{33}$ described similar content during evaluating the role of bacopamonniera and immunomodulation respecttively in wound healing.

On day 3 post-wounding in the present study, many PMNLs were demonstrated in the granulation tissue in the wound area treated by AgNps. PMNLs were markedly decreased on day 7 post-wounding in the same group suggesting that AgNps had a strong anti-inflammatory effect. In normal wound healing especially without bacterial contamination, the inhibition of inflammatory cells and down-regulation of 
pro inflammatory cytokines lead to earlier wound healing conversely, prolongation of the inflammatory phase of wound healing results in the formation of non-healing wounds . ${ }^{34}$

In that respect, Nadworny et al. $(2010)^{35}$ and Rajendran et al. (2018) $)^{36}$ suggested that AgNps had an antiinflammatory effect through induction of neutrophils apoptosis. And so, decreasing the level of pro-inflammatory cytokines such as TNF- $\alpha$, IL-8and TGF- $\beta$ all of which resulted in an overall acceleration of wound healing rate and reduction of hypertrophic scarring.

Tian et al. (2007) ${ }^{37}$ concluded also that the levels of pro-inflammatory cytokine IL-6 mRNA in the wound areas treated with AgNps were maintained at statistically significantly lower levels during the initial period of healing in the site treated with silver nanoparticles.

Bacterial infection is the commonest cause of wound related morbidity. Therefore, protecting the wound from bacterial infection by any agent can promote an increase in healing rate ${ }^{\mathbf{3 6}}$. AgNps had an efficient antimicrobial activity compared to other traditional methods e.g. SSD (dermazine cream) due to their extremely large surface area to volume ratio, which provides better contact with microorganisms. AgNps interact with sulfurcontaining proteins in bacteria membranes, as well as bacterial DNA. Also they attack the respiratory chain and cell division mechanism leading to cell death. Consequently, AgNps are efficient even at a very low concentration, which minimizes the chance for tissue toxicity. ${ }^{38}$

ROS (reactive oxygen species) are produced during cellular respiration. Overproduction of ROS is an important reason for delayed wound healing. AgNps could decrease ROS through up-regulation of catalase activity. So, increased catalase activity through AgNps treatment promoted wound healing ${ }^{39}$.

In the present work, the number of macrophages in AgNps treated group showed a significant increase on day 3 postwounding and highly significant decrease on day 14 post-wounding compared to the control group. Nasrabadi et al. (2011) ${ }^{\mathbf{4 0}}$ showed similar results during studying the effect of Lactobacillus plantarum on cutaneous wound healing in rats on days 3 and 14 post-wounding.

Krzyszczyk et al. (2018) ${ }^{41}$ stated that there are two different activation patterns of macrophages. First, classical macrophage activation in which macrophages act as a pro-inflammatory cells producing proinflammatory mediators such as IL-1, IL-6, IL-12, TNF- $\alpha$ in the earlier phase of wound healing. Second, alternative macrophage activation where macrophage presented as repairing, anti-inflammatory cells, producing anti-inflammatory mediators such as IL-10, TGF- $\square$, PDGF- $\beta$, and VEGF promoting keratinocytes and fibroblast migration, proliferation and angiogenesis at the later stage of wound healing. and transition of macrophages between the two patterns has been assumed to be requisite for the rapid switch from inflammatory phase to proliferative phase in wound healing. You et al. (2017) ${ }^{42}$ suggested that AgNps could regulate the wound's abnormal activation of macrophages and improve the progress of inflammatory stages to accelerate wound healing.

In the current study, the number of newly formed blood vessels in AgNps showed a highly statistical significant increase on day 3 and day 7 post-wounding and highly significant decrease on day 14 in comparison to control group. Similarly, Orlowski et al. (2018) ${ }^{43}$ detected that wounds in mice treated with tannic acidmodified AgNps showed significant increase and significant decrease on day 3 and 14 
postwounding respectively in comparison to the control group.

In contrast to this, there have been results showing that AgNps can act as antiangiogenic molecules where Sheikpranbabu et al. (2009) ${ }^{44}$ found that AgNps can inhibit VEGF-induced cell proliferation, migration and capillary-like tube formation of in-vitro bovine retinal endothelial cells. This discrepancy may be attributed to the way of synthesis or the size of the AgNps used.

In our study chemically synthesized AgNps with a relatively small size $15 \mathrm{~nm}$ were used while Sheikpranbabu et al. (2009) $)^{44}$ used biologically sensitized AgNps with an average relatively large size 40 to 50 $\mathrm{nm}$

Lali and Metcalfe (2014) ${ }^{45}$ mentioned that, the wound environment is characterized by low $\mathrm{pH}$, reduced oxygen tension (hypoxia) and reduced nutrients as a result of loss of vascularity in the wound bed. Therefore, effective wound healing requires vascularization of the newly formed granulation tissue by angiogenesis which is the growth of new blood vessels from preexisting vessels. Johnson and Wilgus $(\mathbf{2 0 1 4})^{\mathbf{4 6}}$ added also that, during the proliferative phase of wound healing, a significant increase in the density of the newly formed blood vessels compared to normal skin is commonly observed as a result of angiogenesis. Later on, these newly formed vessels regress and their number normalize and return to a level close to what is observed in normal skin.

There are many pro-angiogenic growth factors such as bFGF and TGF- $\beta$ but VEGF is unique for its effects on multiple components of wound healing such as angiogenesis, recently re-epithelialization and collagen deposition. VEGF is produced by many cell types as endothelial cells, fibroblasts, platelets, neutrophils and macrophages. VEGF exists in five isoforms;
VEGF-A, VEGF-B, VEGF-C, VEGF-D and placenta growth factor (PGF), the most abundant, available, studied and used in our study is VEGF-A . ${ }^{\mathbf{4 7}}$

Tian et al. (2007) ${ }^{37}$ observed that VEGF mRNA levels stayed at a higher level in the AgNps treated group compared to SSD treated group at all time points monitored during healing in mice.

In the present study, examination of VEGF in immuo-stained sections in AgNps treated group showed that the positive reaction appeared strong on day 3 and 7 post wounding then became weak on day 14 post-wounding. Accordingly Bates and Jones $(\mathbf{2 0 0 3})^{\mathbf{4 8}}$ stated that VEGF was upregulated as early as 3 days after the induction of a wound and that this expression lasted for at least 7 days. Subsequent studies have shown that in fullthickness skin wounds, VEGF mRNA expression declines around day 13 and after 3 weeks is no greater than normal.

Zhou et al. (2015) ${ }^{49}$ mentioned also that after wounding, VEGF secretion are elevated and peak on day 3 and 7 postwounding. Howdieshell et al. (2001) ${ }^{\mathbf{5 0}}$ found that the addition of anti-VEGF inhibits the formation of granulation tissue in the wound indicating an important function of VEGF in angiogenesis that occurs during the proliferative phase.

In the present work, on day 3 and 7 post-wounding there was a statistical increase in the number of fibroblasts which was highly significant in AgNps treated group and significant only in SSD group compared to the control group while on day 14 post-wounding there was a statistical decrease of the number of fibroblasts which was highly significant in $\mathrm{AgNps}$ treated group compared to the control group.

This highly significant decrease on day 14 post-wounding could be explained by Bin and James (2011) ${ }^{\mathbf{5 1}}$ who noted that during wound healing, fibroblasts differentiate into 
myofibroblasts which are responsible for wound contraction. Myofibroblasts become most abundant in the proliferative phase of wound healing and progressively disappear in the later stage of healing where they undergo apoptosis once the wound proceeds to full epithelialization. On the other hand, persistence of myofibroblasts in granulation tissues may lead to the formation of scar tissues e.g. hypertrophic and keloidal scars. Liu et al. (2010) ${ }^{\mathbf{2 1}}$ noted that AgNps can indeed drive the differentiation of fibroblasts into myofibroblasts in the early phase of wound healing, thereby accelerating wound contraction and promote wound healing.

In the present work, the area percent of collagen fibers deposition in Mallory's trichrome stained sections revealed a statistical increase which was significant in AgNps treated group on days 7 and 14 postwounding and non-significant in SSD treated group compared to the control group. Kwan et al. (2011) ${ }^{\mathbf{5 2}}$ postulated that AgNps could regulate the deposition of collagen and inhibiting uncontrolled growth of collagen which is a problem often occurred in natural healing process through a regulated differentiation of fibroblast. Also, it directs proper collagen matrix alignment and spatial arrangement.

\section{Conclusion}

It can be concluded that silver nanoparticles treatment showed the advantage of rapid and adequate healing of excisional skin wounds in male albino rats regarding; epithelialization, neovascularization and collagen fibers deposition compared with the traditional silver sulphadiazine treatment. It might be the treatment of choice particularly for high risk patients.

\section{REFERENCES:}

1. Morton L. and Phillips T. (2016): Wound healing and treating wounds: Differential diagnosis and evaluation of chronic wounds. Journal of the American Academy of Dermatology, 74 (4):589- 605.

2. Walburn J., Vedhara K., Hankins M., et al. (2009): Psychological stress and wound healing in humans: a systematic review and meta-analysis. J Psychosom Res., 67(3):253-71.

3. Rajkumar R., Nadar M. and Paulraj M. (2017): Nanotechnology in Wound HealingA Review. Glob. J. Nanomed., 3(1).

4. Gorski D. and Novella S. (2014): Clinical trials of integrative medicine: testing whether magic works. Trends in Molecular Medicine, 20 (9):473 -476.

5. Mordorski B., Rosen J. and Friedman J. (2015): Nanotechnology as an innovative approach for accelerating wound healing in diabetes. Diabetes Manag., 5(5): 329-332.

6. Ge L., Li Q., Wang M., et al. (2014): Nano silver particles in medical applications: synthesis, performance, and toxicity. Int $\mathbf{J}$ Nanomedicine, 16(9):2399-2407.

7. Majeed S., Danish M., Zahrudin A., et al. (2017): Biosynthesis and characterization of silver nanoparticles from fungal species and its antibacterial and anticancer effect. Karbala International Journal of Modern Science, 4:86-92.

8. Naraginti S., Kumari P., Das R., et al. (2016): Amelioration of excision wounds by topical application of green synthesized, formulated silver and gold nanoparticles in albino Wistarrats.Materials Science and Engineering, 62:293-300.

9. Boroumand Z., Golmakani N. and Boroumand S. (2018): Clinical trials on silver nanoparticles for wound healing (review).Nanomed. J. 5(4): 186-191.

10. Diantoro M., Fitrianingsih R., Mufti N., et al . (2014): Synthesis of silver nanoparticles by chemical reduction at various fraction of MSA and their structure characterization. AIP Conference Proceedings , 1589, 257

11. Panacek A., Kilianova M., Prucek R., et al. (2014):Preparation and in vitro Bactericidal and Fungicidal Efficiency of NanoSilver / Methylcellulose Hydrogel International Journal of Chemical, Molecular, Nuclear, Materials and Metallurgical Engineering,8, (6): 493-499.

12. Fathke, C., Wilson, L., Hutter, J., et al. (2004): Contribution of bone marrow- 
derived cells toskin: Collagen deposition and wound repair. Stem Cells,22(5):812822.

13. De Melo Rambo C., Silva J., Serra A., et al. (2014): Comparative analysis of low-level lasertherapy $(660 \mathrm{~nm})$ on inflammatory biomarker expression during the skin wound-repair processin young and aged rats. Lasers Med Sci.,29 (5):1723- 1733.

14. Jain J., Arora S., Omray P., et al. (2009): Silver nanoparticles in therapeutics: development of an antimicrobial gel formulation for topical use.Mol Pharm., 6(5):1388-1401.

15. Aliabdi A. and Valadaan V. (2016): Comparison between the Effect of Silymarin and Silver Sulfadiazine on Burned Wound Healing in Rats.Bulgarian Journal of Veterinary Medicine, 19 (3):224232.

16. Drury, R. and Wallington, E. 1980.Carleton's Histologiacal Technique, 5th edition, Oxford University Press, New York and Tronto, p. 520 -526.

17. Bratthauer G. (2010): The avidin-biotin complex $(\mathrm{ABC})$ method and other avidinbiotin binding methods. Methods Mol Biol., 588:257-270.

18. Sawilowsky S. (2005): Misconceptions leading to choosing the $t$ test over the Wilcoxon Mann-Whitney Test for Shift in Location Parameter. JMASM, (4): 598-600.

19. Dorsett-Martin W. (2004):Rat models of skin wound healing: A review. Wound Repair Regen., 12(6):591-599.

20. Kumar V., Khan A. and Nagarajan K. (2013): Animal models for the evaluation of wound healing activity. International Bulletin of Drug Research, 3(5): 93-107.

21. Liu X., Lee P., Ho C. et al. (2010): Silver nanoparticles mediate differential responses in keratinocytes and fibroblasts during skin wound healing. ChemMedChem., 5 (3):468-475.

22. 22- Gál P., Kilik R., and Mokry M. (2008): Simple method of open skin wound healing model in corticosteroid-treated and diabetic rats: standardization of semi-quantitative and quantitative histological assessments. Veterinárnímedicína, 53(12):652-659.
23. Tan N. and Wahli W. (2013): Studying Wound Repair in Mouse. CurrProtoc Mouse Biol., 3(3):171-185.

24. Hendi A. (2011): Silver nanoparticles mediate differential responses in some of liver and kidney functions during skin wound healing. Journal of King Saud University (Science), 23, 47-52.

25. Fawzy H., Shawarby A., Kalleny N., et al.(2018): Comparative Study on the Effect of Silver Nanoparticles versus Silver Sulfadiazine in Diabetic Wound Healing in Albino Rat: a Histological Study. The Egyptian Journal of Hospital Medicine, 73 (2):6042- 6051.

26. Zhang X., Liu Z, Shen W., et al. (2016): Silver Nanoparticles: Synthesis, Characterization, Properties, Applications, and Therapeutic Approaches. Int J Mol Sci. $13 ; 17(9)$.

27. Khafaga A., Abu-Ahmed H., El-Khamary A., et al. (2018): Enhancement of Equid Distal Limb Wounds Healing by Topical Application of Silver Nanoparticles. Journal of Equine Veterinary Science, 61 :( 76-87).

28. Sundaramoorthi C., Kalaivani M., Palanisamy S., et al. (2009): Biosynthesis of silver nanoparticles from Aspergillusniger and evaluation of its wound healing activity in experimental rat model. International Journal of PharmTech Research,1(4): 15231529.

29. Chen D., Hao H., Fu X., et al. (2016): Insight into Re-epithelialization: How Do Mesenchymal Stem Cells Perform. Stem Cells International, (3):1-9.

30. Pastar I., Stojadinovic O., Yin N., et al. (2014): Epithelialization in Wound Healing: A Comprehensive Review. Adv Wound Care (New Rochelle), 3(7): 445-464.

31. Bhagavathy S. and Kancharla S. (2016): Wound healing and angiogenesis of silver nanoparticle from Azadirachtaindicain diabetes induced mice International Journal of Herbal Medicine , 4(5): 24-29

32. Murthy S., Gautam M., Goel S., et al. (2013): Evaluation of in vivo wound healing activity of Bacopamonniera on different wound model in rats. Biomed Res Int., 2013:97-106. 
33. Park J. and Barbul A. (2004):Understanding the role of immune regulation in wound healing. Am J Surg., 187(5):11 -16.

34. Franková J., Pivodová V., Vágnerová H., et al. (2016): Effects of silver nanoparticles on primary cell cultures of fibroblasts and keratinocytes in a wound-healing model. $\mathbf{J}$ ApplBiomaterFunctMater , 14(2): 137-142

35. Nadworny P., Wang j., Tredget E.(2010): Anti-inflammatory activity of nanocrystalline silver-derived solutions in porcine contact dermatitis. Journal of Inflammation, 7(1):13-19.

36. Rajendran N., Kumar S., Houreld N., et al. (2018): A review on nanoparticle based treatment for wound healing. Journal of Drug Delivery Science and Technology, 44: 421-430.

37. Tian J., Wong K., Ho C., et al. (2007): Topical delivery of silver nanoparticles promotes wound healing. ChemMedChem.,; 2(1):129 -136.

38. Oyarzun-Ampuero F., Vidal A., Miguel C., et al. (2015): Nanoparticles for the Treatment of Wounds. Current pharmaceutical design, 21(29): 4329-4341.

39. Pothireddy S., Kaliki A., Yegireddy M., et al. (2016):Evaluation of the wound healing efficacy of chemical and phytogenic silver nanoparticles. IET Nanobiotechnol., 10(5):340-348.

40. Nasrabadi H., Ebrahimi T., Banadaki D., et al. (2011): Study of cutaneous wound healing in rats treated with Lactobacillus plantarumon days 1, 3, 7, 14 and 21 . Veterinary Medicine, 19 (3) : 224-232.

41. Krzyszczyk P., Schloss R., Palmer A. et al. (2018): The Role of Macrophages in Acute and Chronic Wound Healing and Interventions to Promote Pro-wound Healing Phenotypes. Front Physiol., 1(9):419-425.

42. You C., Li Q., Wang X., et al. (2017):Silver nanoparticle loaded collagen/chitosan scaffolds promote woundhealing via regulating fibroblast migration and macrophage activation. Sci Rep., 5; 7(1): 10489.

43. Orlowski P., Zmigrodzka M., Tomaszewska E. et al. (2018):Tannicacid-modified silver nanoparticles for wound healing: the importance of size. Int $\mathrm{J}$ Nanomedicine, 16(13):991-1007.

44. Sheikpranbabu S., Kalishwaralal K., Venkataraman D., wt al. (2009): Silver nanoparticles inhibit VEGF-and IL-1betainduced vascular permeability via $\mathrm{Src}$ dependent pathway in porcine retinal endothelial cells. J. Nanobiotechnol. 7, 819.

45. Lali F. and Metcalfe A. (2014): The role of angiogenesis in wound healing, scarring and tissue regeneration. Pmfa news journal, 2 (1):417-425.

46. Johnson K. and Wilgus T. (2014): Vascular Endothelial Growth Factor and Angiogenesis in the Regulation of Cutaneous Wound Repair. 49- Johnson K. and Wilgus T. (2014): Vascular Endothelial Growth Factor and Angiogenesis in the Regulation of Cutaneous Wound Repair. AdvWound Care

Rochelle).,1;3(10):647-661.

(New

47. Bao P., Kodra A., Ehrlich H., et al. (2009): The Role of Vascular Endothelial Growth Factor in Wound Healing. J Surg Res., 153(2):347-358.

48. Bates D.andJones R. (2003): The role of vascular endothelial growth factor in wound healing. Int $\mathbf{J}$ Low Extrem Wounds,2(2):107-120.

49. Zhou K., Ma Y., and Brogan M. (2015): Chronic and non-healing wounds: The story of vascular endothelial growth factor. Med Hypotheses., 85(4):399-404.

50. Howdieshell T., Callaway D.andWebb W. (2001): Antibody neutralization of vascular endothelial growth factor inhibits wound granulation tissue formation. J Surg Res.,96(2):173-82.

51. Bin L. and James H. (2011): Fibroblasts and Myofibroblasts in Wound Healing: Force Generation and Measurement. J Tissue Viability, 20(4): 108-120.

52. Kwan K., To M., Yeung K., et al. (2011): The modulating action of silver nanoparticles on collagen deposition in producing scarless wound healing. Nanomedicine: Nanotechnology, Biology, and Medicine, 7 (2011) 497-504. 
دور جسيمات الفضه متناهيه الصغر في تسريع التئام الجروح الجلدية في الجرذان دراسة هستولوجية

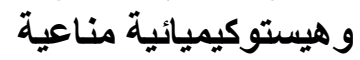

ياسمين رمضان, مها خالد العشري, ابتسام أحمد بهي الدين , عزه صلاح الدين سليمان , نجوي ابراهيم النفياوي, مها مصطفي أحمد زكريا

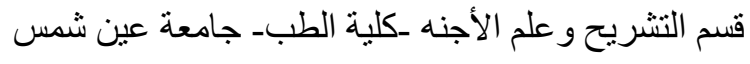

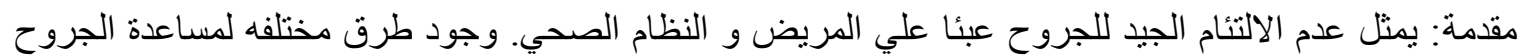

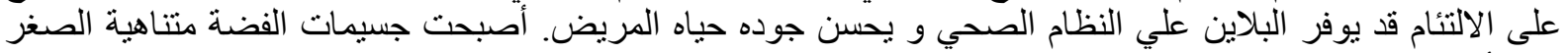

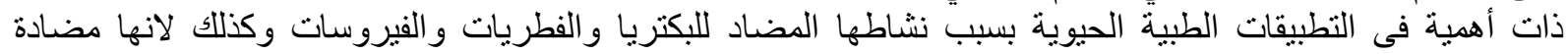

الهدف من الدراسة: كان الهدف من الدراسة الحاليه هو التحقق من الدور المحتمل لجسيمات الفضة متناهية الصغر

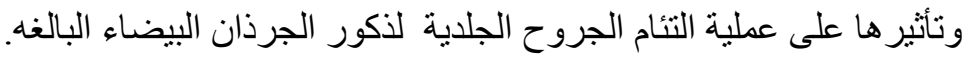

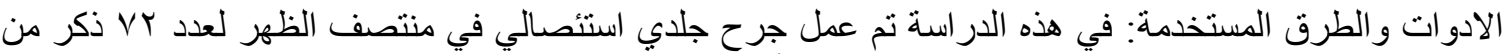

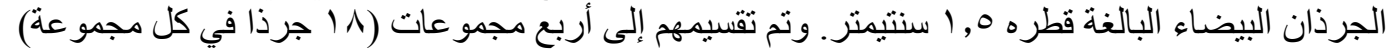

$$
\text { ا. المجمو عة الأولى (المجموعة الضابطة). }
$$

r ا المجموعة الثانية (المعالجة بالميثيل سليلوز هيدروجيل). r. المجمو عة الثالثة (المعالجة بالسلفر سلفاديازين (ديرمازين كريم). ع. المجمو عة الر ابعة (المعالجة بجسيمات الفضة متناهية الصغر ).

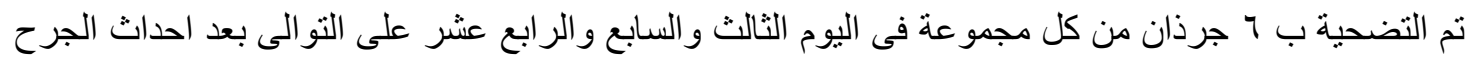

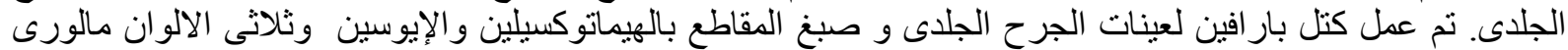

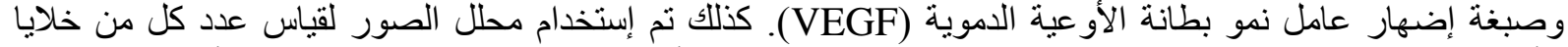

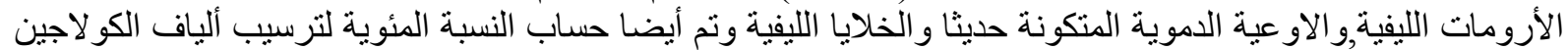

وتم تحليل البيانات إحصائيا.

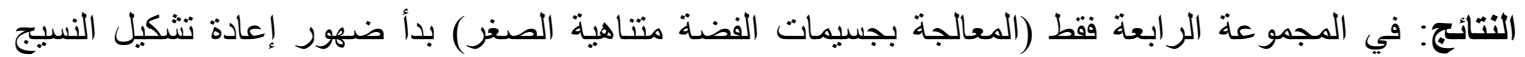

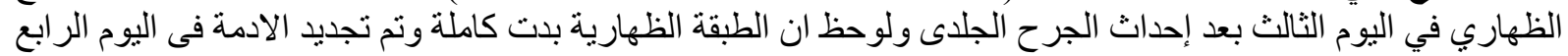

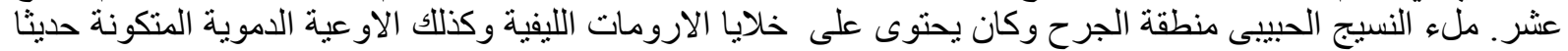

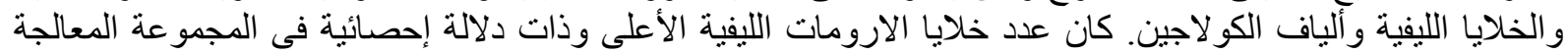

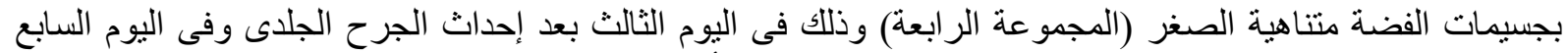

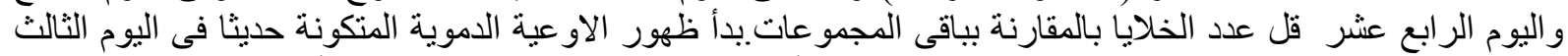

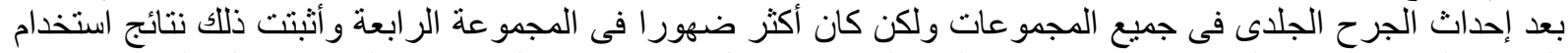

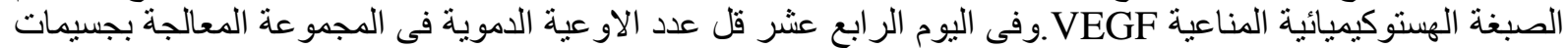

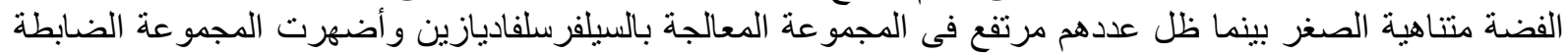

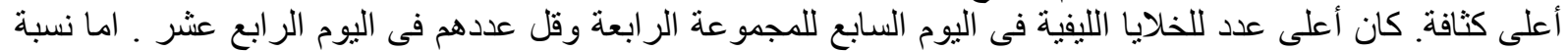

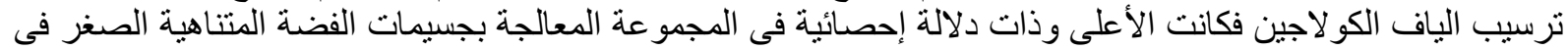

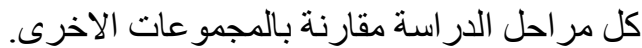

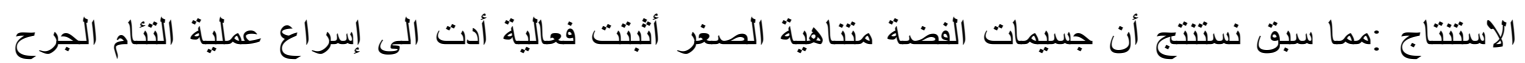

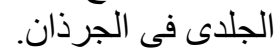

